\title{
CONTRAST AND REALLOCATION OF EXTRANEOUS REINFORCERS AS A FUNCTION OF COMPONENT DURATION AND BASELINE RATE OF REINFORCEMENT
}

\author{
Anthony P. MaLean
}

\author{
UNIVERSITY OF CANTERBURY, NEW ZEALAND
}

\begin{abstract}
Four pigeons responded on multiple schedules arranged on a "main" key in a two-key experimental chamber. A constant schedule component was alternated with another component that was varied over conditions. On an extra response key, conjoint schedules of reinforcement that operated in both components were arranged concurrently with the multiple schedule on the main key. On the main key, changes in reinforcement rate in the varied component were inversely related to changes in response rates in the constant component (behavioral contrast). On the extra key, some reinforcers were reallocated between components, depending on the schedules in effect on the main key in the varied component. In the varied component, the obtained rates of reinforcement on the extra key were inversely related to main-key reinforcement rate. In the constant component, extra-key reinforcer rates were positively related to main-key reinforcer rates obtained in the varied component, and were not a function of response rates on the extra key. In two comparisons, the rate at which components alternated and the value of the main-key schedule in the constant component were varied. Consistent with earlier work, long components reduced the extent of contrast. Reductions in contrast as a function of component duration were accompanied by similar reductions in the extent of reinforcer reallocation on the extra key. In the second comparison, lowering the rate of reinforcement in the constant component increased the rate at which extra-key reinforcers were obtained, reduced the extent of reinforcer reallocation, and reduced contrast. Overall, the results are consistent with the suggestion that some contrast effects are due to the changes in extraneous reinforcement during the constant component, and that manipulations of component duration, and manipulations of the rate of reinforcement in the constant component, affect contrast because they influence the extent of extraneous reinforcer reallocation.

Key words: behavioral contrast, reallocation hypothesis, extraneous reinforcers, component duration, component value, multiple schedules, concurrent schedules, key peck, pigeons
\end{abstract}

Behavioral contrast refers to a change in responding in one multiple-schedule component that occurs when reinforcement conditions are varied in a second, alternated component. Specifically, positive behavioral contrast is an increase in response rate that is produced by reducing reinforcement in the alternate component. Negative contrast is the reverse; responding decreases in the constant component when reinforcement is increased in the other component. Responding in each component of a multiple schedule occurs in the context of two sources of reinforcement-reinforcement for the target response, and "extraneous" reinforcement gained by engaging

The research described here was supported by grants from the University of Canterbury (1787597) and from the Psychology Department. I am grateful to Tony Nevin for helpful comments on an earlier version of the manuscript, and to Neville Blampied for assistance in the laboratory. For reprints, write to the author at Department of Psychology, University of Canterbury, Private Bag 4800, Christchurch, New Zealand. in other behavior such as grooming, resting, and exploring the experimental space. Thus, the changes in response rate that constitute behavioral contrast might be viewed as changes in the allocation of behavior between concurrently available sources of reinforcement, a relation that may be described in terms of the matching law (Baum, 1974) applied to behavior within each component.

Two alternative theories of contrast are consistent with the matching law. According to one, a direct-interaction model, the allocation of behavior between two operant classes (responding and other behavior) is governed by the relative rates of reinforcement in both the constant and the varied components. Such interaction requires extension of the matching law to include a term for reinforcement in one component in the expression predicting behavior for the other component (see Herrnstein, 1970, McLean, 1991, and Williams \& Wixted, 1986, for examples), but is otherwise consistent with the general approach given in the matching law. These various direct-inter- 
action theories of contrast have several differences, but have in common the idea that temporally distant components of multiple schedules interact over time to determine responding in each component.

According to the second approach, the interaction of components is mediated by changes in extraneous reinforcement. When reinforcement in a varied component is increased, negative contrast occurs in the other, unchanged component because extraneous reinforcers are transferred from the enriched, varied component to the constant component. The increase in extraneous reinforcement reduces the efficacy of reinforcement for responding relative to that for other behavior, and produces the well-documented process of concurrent interaction (Catania, 1963; Rachlin \& Baum, 1972) within the constant component. Similarly, positive behavioral contrast occurs when the varied component is reduced in value because relative reinforcement in the constant component increases when larger amounts of extraneous reinforcement are taken in the low-valued, varied component. This account of contrast is known as the extraneous reinforcer reallocation hypothesis (see McLean, 1992; McLean $\&$ White, 1983). It attributes contrast to concurrent interaction, which may be viewed as a process of competition between alternative sources of reinforcement that are simultaneously available, rather than successive interaction over time. A similar theory was proposed by Staddon (1982) in which a change in competing behavior, rather than competing reinforcement, was invoked in the constant component. Both versions may be characterized as "competition" theories of contrast, and both differ from direct-interaction theories in that they attribute contrast to changes that occur within the constant component rather than the successive interaction of successively presented reinforcement schedules. However, the two versions of competition theory differ in several respects, and the present work will focus on the extraneous-reinforcer reallocation view outlined above and described in detail by McLean (1992) and McLean and White (1983).

The reallocation view of contrast has recently gained considerable support in a study that demonstrated the reallocation of extraneous reinforcers (McLean, 1992). In this study, an explicit source of extraneous rein- forcement was arranged in components of a multiple schedule by arranging conjoint schedules of reinforcement for responses on a second, "extra" response key. The conjoint schedules were intended to emulate the presumed properties of naturally occurring schedules of extraneous reinforcement, and the subjects were exposed to a series of conditions in which the reinforcement schedule in effect on the main key was varied for one component and remained constant for the other. The result was that the obtained rate of extra-key reinforcers increased in the constant component when the varied component was enriched and decreased when the varied component was made lean. Thus, the constant component was only constant with respect to reinforcement on the main key-changes in competing, extra-key reinforcement occurred over conditions that were consistent with contrast on the main key. A constraint on reallocation of extra-key reinforcers, imposed by canceling reinforcers arranged on the extra key at the end of components, reduced both contrast and reallocation and confirmed that changes in extra-key reinforcement in the constant component did not arise from changes in constant-component behavior (a relation that should be unaffected by the constraint). Overall, McLean concluded that the results support the contention that reallocation of extraneous reinforcers may cause contrast. Criticisms of this interpretation of the data, offered by Williams and Wixted (1994), are based on the behavioral competition theory rather than on reinforcer reallocation and will be discussed in detail below.

The present work was conducted to explore further the relation between reinforcer reallocation and behavioral contrast by examining the correlation between them over manipulations that have been shown to affect contrast. For example, the magnitude of contrast is known to be reduced when components alternate slowly rather than rapidly (e.g., McSweeney, 1982; Williams, 1979), at least when pigeons are used as subjects and the key peck is used as the response. It seems possible that extended exposure to components may also influence the extent to which extraneous reinforcers are reallocated between components, and that changes in reallocation may mediate the effect of component duration on contrast.

A second manipulation that has been shown to affect the extent of behavioral contrast is 
the baseline schedule of reinforcement. Overall, the evidence suggests that contrast is larger in a constant component that has low value (i.e., low frequency, immediacy, or magnitude of reinforcement; Harper \& McLean, 1992; Nevin, 1974; Nevin, Mandell, \& Atak, 1983; Spealman \& Gollub, 1974) than in one with high value. However, with the exception of Spealman and Gollub's study, these results were all obtained in procedures in which multiple schedules contained three components; two components with different reinforcement schedules were constant throughout the experiment, and a third was varied. Manipulating reinforcer rate in the varied component produced different amounts of contrast in the other two components, depending on whether they were rich or lean in reinforcement. In the more standard two-component arrangement, McSweeney, Dougan, Higa, and Farmer (1986) found the exact opposite: Contrast was stronger when the baseline schedule was rich. Unpublished data obtained in the present author's laboratory also failed to confirm stronger contrast in low-valued components with twocomponent multiple schedules. An additional study by Reynolds (1963) found that except when the constant component was very lean, contrast was easier to produce with low-valued constant components. Overall, the results of Reynolds' study suggest a bitonic function relating the magnitude of contrast to the value of the constant component. Thus, the status of baseline schedule value as a determinant of contrast seems to be uncertain and deserves further investigation in two-component schedules.

Accordingly, the present study examined changes in contrast over manipulations of component duration and baseline rate of reinforcement, and related these changes to changes in extraneous reinforcer reallocation. The use of an explicit source of alternative reinforcement seems to be a valuable method of assessing the extent to which subjects reallocate extraneous reinforcers; thus, the conjoint schedules on an extra key, used by McLean (1992), were also used here. On the main key, the value of a varied component was changed over five values while the other component was constant. Contrast and reallocation were compared over conditions in which the component duration and the value of the constant component were varied.

\section{METHOD}

Subjects

Four homing pigeons, with previous experience in the two-key procedures used here (McLean, 1992), were maintained at $80 \%$ to $85 \%$ of free-feeding weights. Water and grit were always available in home cages, where supplementary feed of mixed grain was given shortly after experimental sessions if required to maintain prescribed weights.

\section{Apparatus}

Four similar experimental chambers $(34 \mathrm{~cm}$ by $34 \mathrm{~cm}$ by $32 \mathrm{~cm}$ ) each contained an interface panel with three response keys, one mounted centrally and the others $9 \mathrm{~cm}$ on either side of it, all $21 \mathrm{~cm}$ above the grid floor. The center key and houselight were not used. Pecks on either side key that exceeded approximately $0.15 \mathrm{~N}$ produced a relay click and extinguished for $50 \mathrm{~ms}$ the red or green light illuminating the key from behind. A hopper containing wheat was mounted in the center of the interface panel $6 \mathrm{~cm}$ above the floor and was raised and lit with white light during reinforcement. Scheduling and recording of all experimental events were accomplished using an IBM-AT ${ }^{\circledR}$ compatible computer running $\mathrm{MED}-\mathrm{PC}^{\circledR}$ software and using MED Associates interfacing.

\section{Procedure}

Subjects were always trained in the chambers assigned to them at the beginning of the experimentation described in McLean (1992). Sessions lasted $40 \mathrm{~min}$ and normally were conducted 7 days per week. Responses on the left ("main") key were reinforced according to a multiple schedule with two variable-interval (VI) components, with 3-s access to wheat as reinforcement. Components alternated strictly, at intervals that were varied in the experiment (see Table 1). Reinforcers that were arranged but not obtained by the end of a component were never canceled and could be obtained when the same component was next presented. The VI schedules comprised 12 intervals, from the Fleshler and Hoffman (1962) progression, that were sampled at random without replacement until all 12 had been used. Separate schedules were always used for the two components. In each series of conditions, one component remained constant in value while the 


\section{Table 1}

Reinforcement schedules, component durations, and number of sessions of training given for the constant and varied components in each condition. Conditions are listed in the order in which they were experienced. Schedules are given only for the main key, because contingencies on the extra key were constant throughout the experiment (see Procedure).

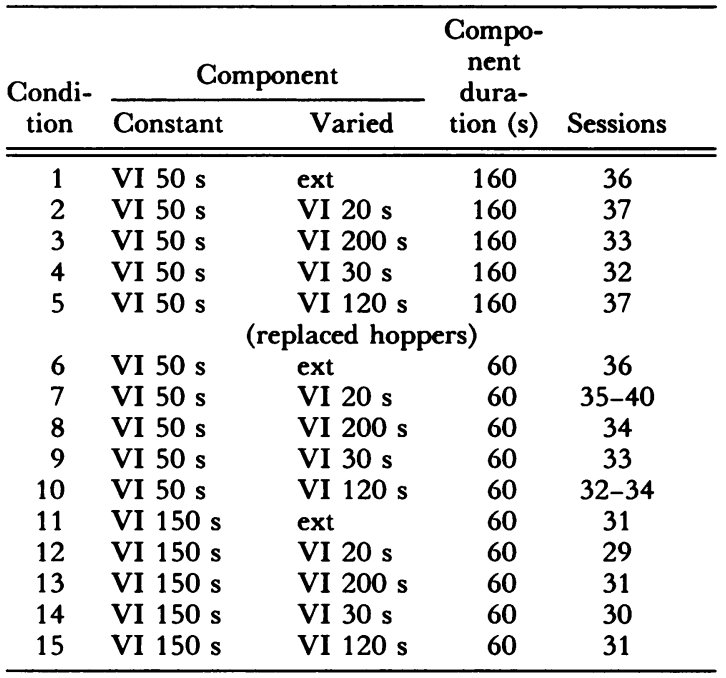

other was varied so as to arrange 0 to 180 reinforcers per hour in different conditions.

The color (red or green light depending on the component in effect) that appeared on the main key was presented at the same time on the right ("extra") key. In all conditions, a changeover delay of $3 \mathrm{~s}$ prevented immediate reinforcement of a response that directly followed one on the alternative key (i.e., a changeover) or of any response within $3 \mathrm{~s}$ of any changeover. The contingencies arranged on the extra key were designed to imitate presumed properties of naturally occurring schedules of extraneous reinforcement and were identical to those in McLean (1992). Specifically, the schedule included five separate VI 100-s schedules running simultaneously and a variable-ratio (VR) 425 schedule that operated only when none of the VI schedules had timed out. For one of the VI schedules, reinforcer availability was signaled by turning the extra key white, whereupon a fixed ratio (FR) of five responses was required for reinforcement (i.e., a chained VI FR schedule). Except when timed out, these schedules operated continuously throughout sessions, and arranged reinforcers were never canceled at the end of components. Thus, unlike the independent schedules used on the main key, reinforcers that were arranged in one component could be obtained during the following presentation of the alternate component. Responses on the extra key were reinforced if any of the schedules had timed out, and if several had timed out then as many successive responses on the extra key would each produce a reinforcer and restart one of the timed-out schedules. Reinforcers from the VR and signaled VI schedules were of 3-s duration, and others varied unpredictably between 1 and 2 s. These contingencies were arranged in order to make possible an accumulation of reinforcement on the extra key that would remain available after components alternated, and in that sense are similar to naturally occurring schedules of extraneous reinforcement which are not confined to individual components of the multiple schedule. In addition, they imitate likely properties of extraneous reinforcers in that they are available from several sources (schedules), some of which are ratio and some of which are interval schedules.

The subjects, apparatus, and procedure were all the same as in McLean (1992), and the present conditions were conducted immediately after collection of the data described there, so no preliminary training was required. Except in one case of error, training continued in each condition for at least 30 sessions, after which conditions were changed at the experimenter's convenience. In the author's experience, this is more than sufficient for performance to stop changing systematically after a change in experimental conditions. The effect of day-to-day fluctuations in response rate was minimized by taking performance from the final 10 (rather than five) sessions of training in each condition.

The experimental conditions used and the number of sessions of training given in each are summarized in Table 1. Occasional days when equipment failed or a subject was overweight resulted in different numbers of sessions for different subjects in Conditions 7 and 10. Over two series of conditions, components alternated at intervals of $160 \mathrm{~s}$ or $60 \mathrm{~s}$. The VI schedule used on the main key in the constant component was a VI 50-s schedule. In a third series, component duration was $60 \mathrm{~s}$ and the constant multiple-schedule component was VI $150 \mathrm{~s}$. Very short component durations seem 
likely to disrupt the concurrent performances and reinforcer rates arranged during components, especially with the changeover delay in the present procedure, but to increase the number of component durations studied here an earlier data set was also included in the analysis. When combined with data from McLean (1992), which were obtained with 40-s components immediately before the present study, the present conditions yielded three different component durations and two different baseline schedules of reinforcement for the study of contrast and reallocation. Note that after examining the 160 -s component series, several other conditions, not reported here, followed replacement of the grain hoppers as part of an upgrade to the laboratory apparatus. The effects of this change appeared to have vanished by the time the 60 -s component series was conducted.

\section{RESULTS}

The results of manipulating component duration and constant-component schedule values are described separately below. Because the major results are described in terms of derived measures (proportions), the Appendix gives absolute response and reinforcer rates from all conditions, corrected for reinforcement time. All pecks on both keys were included in the analyses, including those that satisfied the FR requirement in the chained VI FR schedule. Here and in the Appendix, the results are based on the last 10 sessions in each condition.

\section{Component Duration}

Analyses of response rates on the main key during the varied component will not be presented here, but the data are available in the Appendix. Throughout the experiment, they were a clearly hyperbolic function of reinforcer rates, as would be expected. Figure 1 gives data for the main key in the constant component, plotted as a function of reinforcers per hour on the main key in the varied component. The uppermost panels reproduce data from McLean (1992) with 40-s components, and the middle and lower panels give data obtained with 60-s and 160-s components, respectively. Responding is expressed as the ratio of response rate in a condition relative to the mean response rate on the main key for the constant component over all conditions in the series. This adjustment provides a common verticalaxis scale for all conditions and eliminates the effects of changes in overall response rate between series (see, e.g., the similar treatment used to compare changes in response rates between conditions by Nevin et al., 1983).

Behavioral contrast was assessed using the broad definition of an inverse relationship between response rate on the main key during the constant component and reinforcer rate on that key during the changed component (but see McSweeney \& Norman, 1979, for a narrower definition). There was clear behavioral contrast, in that response rate decreased in the constant component as reinforcement rate was increased in the varied component. To facilitate comparison of the extent of behavioral contrast, a straight line was fitted. The slopes of these lines, followed by their standard errors, are given in parentheses in each panel. These were multiplied by 100 because of the different scales on the two axes.

With one clear exception (Bird D6 with 160-s components), contrast appeared to be stronger when component durations were short (40 or $60 \mathrm{~s}$ ) than when long components (160 s) were used. The contrast effects were generally described reasonably well by the straight lines (although note the data from Bird D6 with 40-s and 160-s components), and the slopes of these lines confirm weaker contrast with long components, with the exception noted above. Thus, the present data replicate the common finding that contrast is a decreasing function of component duration (McSweeney, 1982; Williams, 1979).

Figure 2 shows obtained rates of extra-key reinforcement in the constant and varied components, plotted as a function of main-key reinforcers per hour in the varied component. Extra-key reinforcer rate in each condition is expressed relative to the mean for the series, as was done with response rate in Figure 1. This adjustment was used partly to retain consistency with Figure 1. In addition, because reinforcer rate on the main key in the constant component did not vary, this measure indicates the effect that changes in reinforcer rate on the extra key had on relative reinforcement (main key to extra key) in the component; this would be less clear if absolute reinforcer rates were plotted. This is appropriate because the reinforcer reallocation hypothesis attributes 

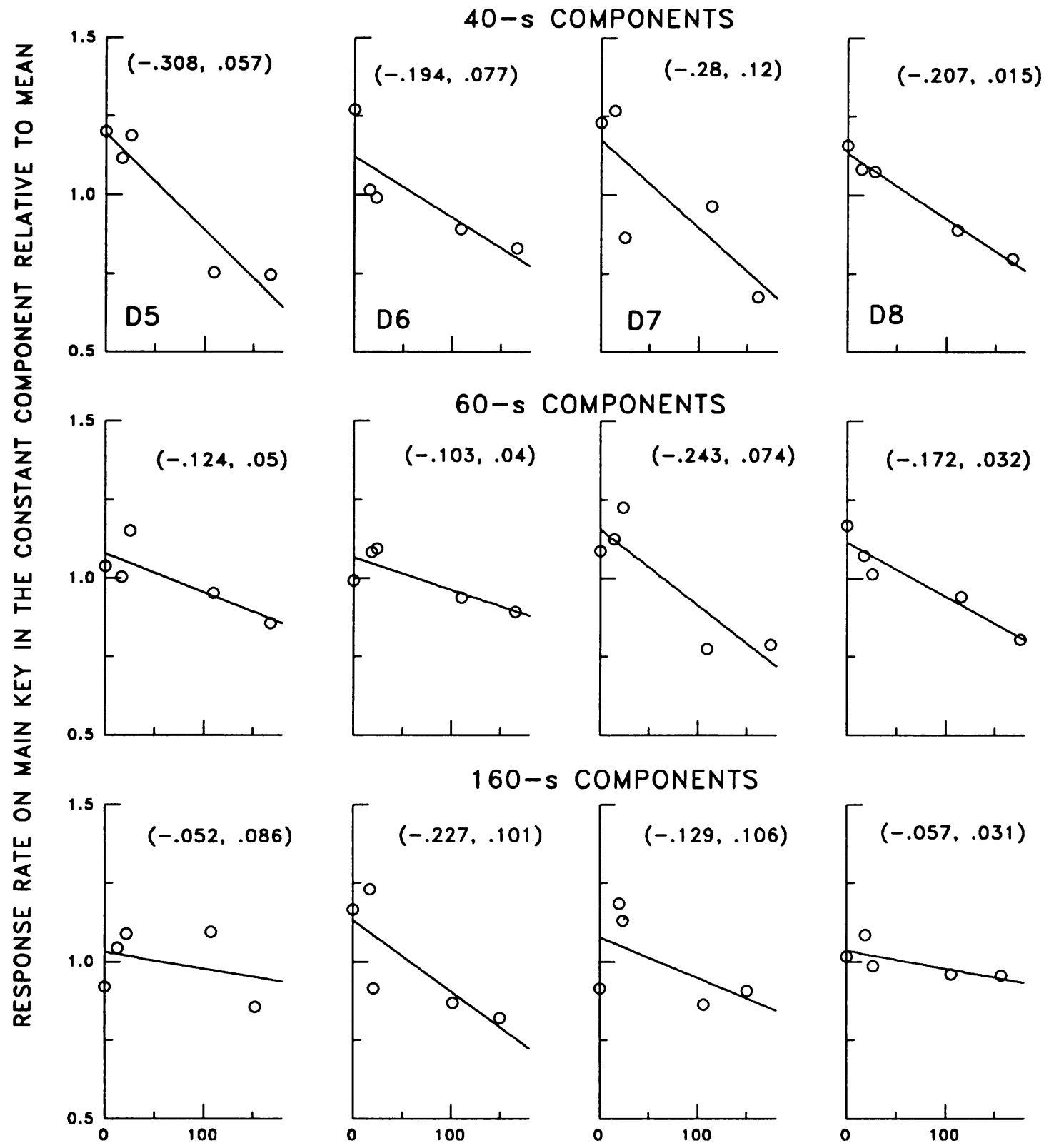

\section{MAIN-KEY REINFORCERS PER HOUR IN VARIED COMPONENT}

Fig. 1. Relative response rates on the main key during the constant component, plotted as a function of reinforcers per hour on the same key in the varied component, for each bird. Response rates in each condition were divided by the mean rate for the series of conditions. Straight lines are least squares regression lines, fitted to describe contrast effects. The slopes, and their standard errors, are given in each panel. The upper row gives previously published data obtained with 40-s components (McLean, 1992), and subsequent rows give data from 60-s and 160-s components, respectively. 
40-s COMPONENTS
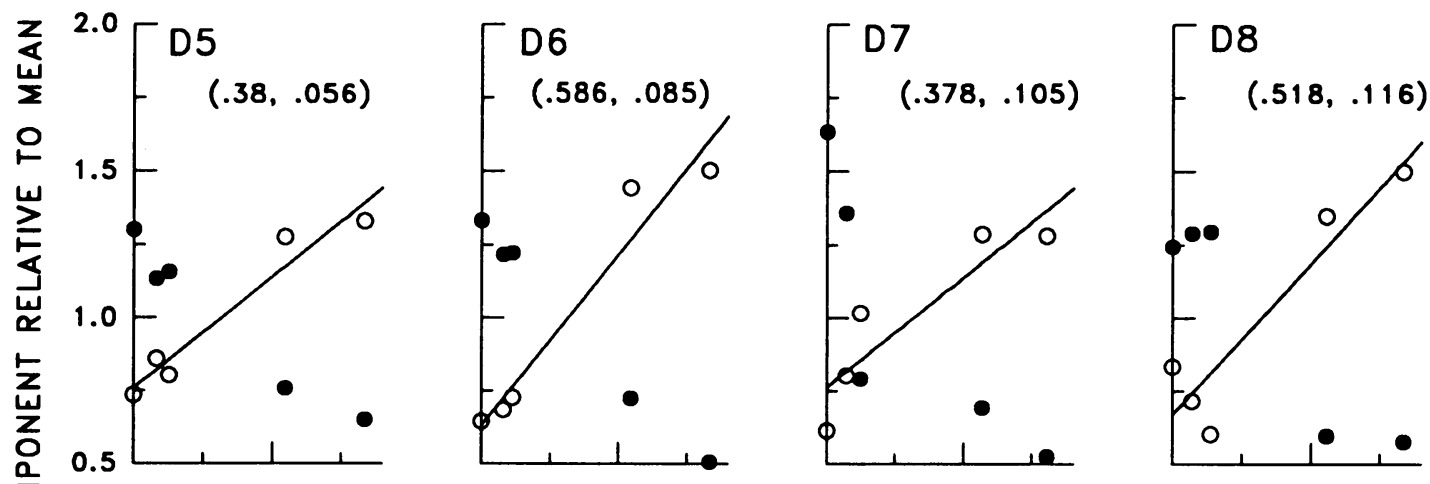

\section{0-s COMPONENTS}
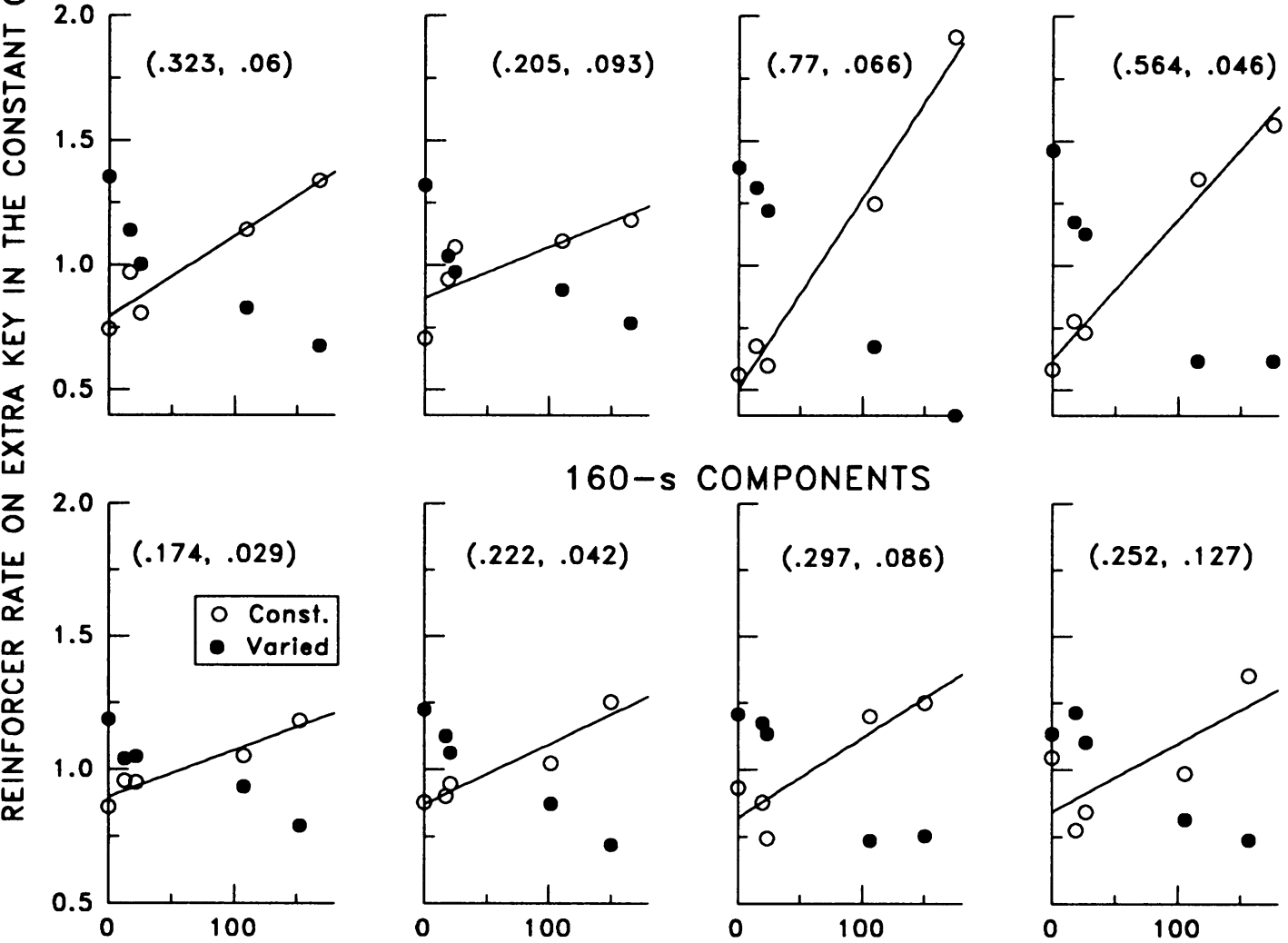

\section{0-s COMPONENTS}

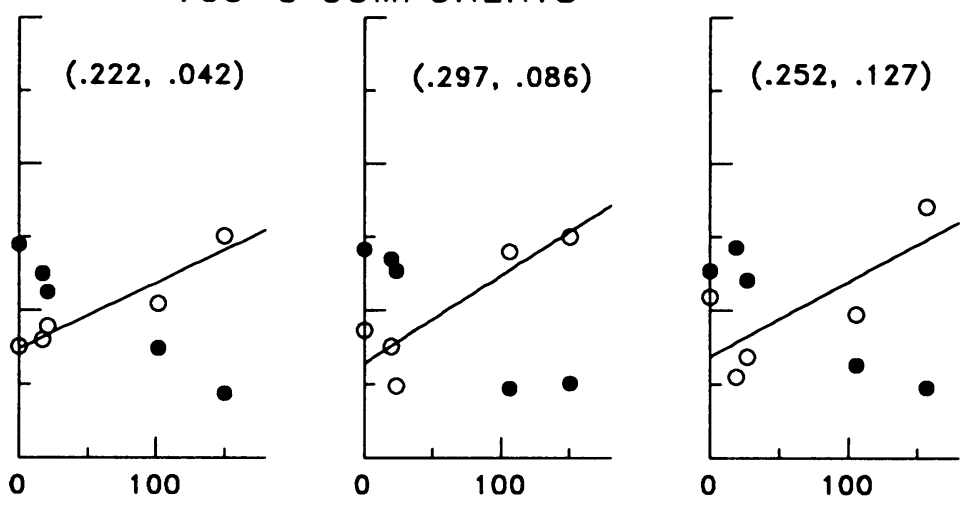

\section{MAIN-KEY REINFORCERS PER HOUR IN VARIED COMPONENT}

Fig. 2. Relative reinforcement rates on the extra key in the constant component (unfilled circles) and the varied component (filled circles), plotted as a function of reinforcers per hour on the main key in the varied component. Reinforcer rates on the extra key in each condition were divided by the mean rate obtained for the series of conditions. Straight lines are regression lines fitted to describe reallocation of reinforcers, and the slopes and their standard errors are given in parentheses in each panel. The upper row gives previously published data obtained with 40-s components (McLean, 1992), and subsequent rows give data from 60-s and 160-s components, respectively. 


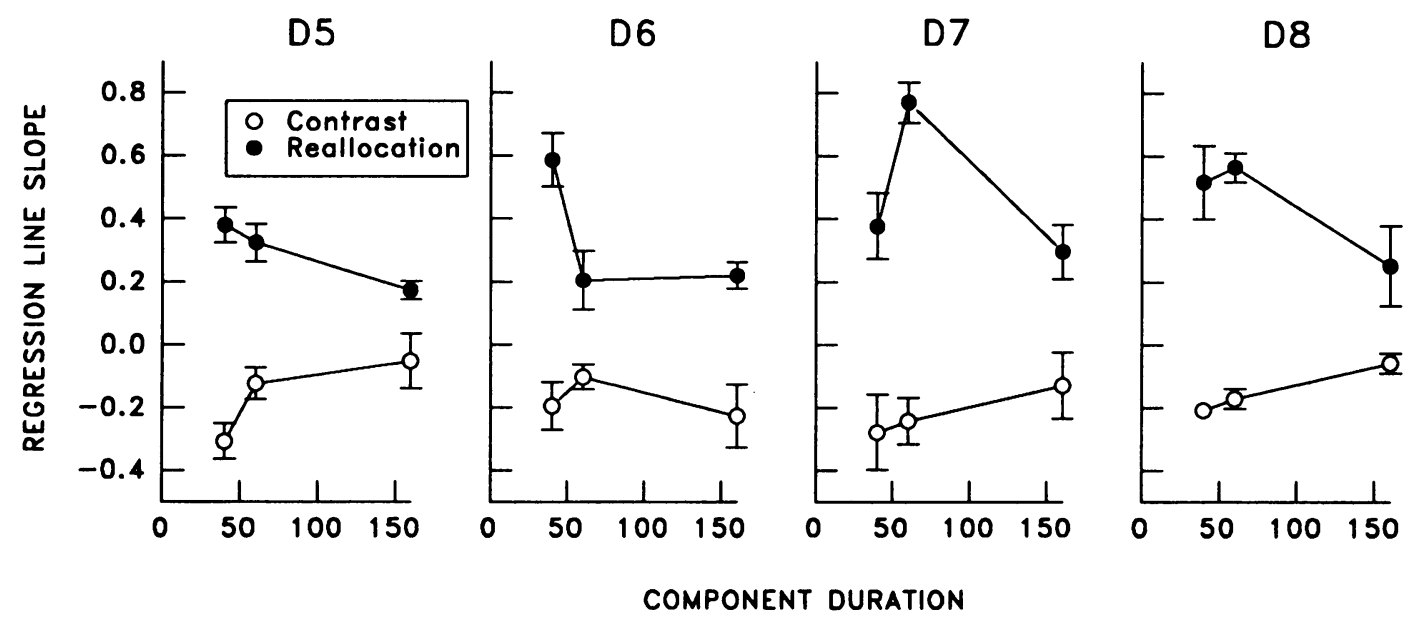

Fig. 3. Slopes of the regression lines fitted to describe contrast (unfilled circles) and reallocation (filled circles) in Figures 1 and 2, plotted as a function of component duration for each bird. Data for 40-s components are from McLean (1992). Error bars display the standard errors of the slopes.

changes in main-key responding to changes in relative reinforcement in the constant component.

As main-key reinforcement increased in the varied component, extra-key reinforcers obtained in that component decreased and those in the constant component increased. That is, extra-key reinforcers were transferred or "reallocated" between components. In particular, despite constant arranged rates of reinforcement on the extra key across conditions, the rate obtained in the constant component was an increasing function of main-key reinforcement in the varied component, as would be necessary for reallocation to cause contrast in responding on the main key. With the exception of Bird D6 with 60-s components, reinforcer reallocation appeared to be stronger with short components (40 s or $60 \mathrm{~s}$ ) than with long components $(160 \mathrm{~s})$. Slopes of straight lines fitted to data confirm reallocation of reinforcers on the extra key in that they are consistently positive, and with the exception noted above, they confirm the effect of component duration in that slopes were consistently shallower with 160 -s components.

Figure 3 summarizes the main results of manipulation of the component duration. For each subject, the slopes of the contrast and reallocation functions are plotted over the three component durations. The effect of component duration on reinforcer reallocation was least clear in the data for Bird D7, which show a nonmonotonic function. Similarly, Bird D6 shows a nonmonotonic function for size of contrast as a function of component duration. However, overall it seems clear that contrast and reallocation both decreased as component duration increased. At an ordinal level, the data are therefore consistent with the suggestion that the effect of component duration on contrast may result from changes in the extent of reallocation.

\section{Value of the Constant Component}

Contrast and reinforcer reallocation were compared over conditions in which the constant-component schedule was relatively rich (VI 50 s) or lean (VI 150 s). Only Conditions 6 through 15 , with 60 -s component durations, were considered. Figure 4 shows main-key response rates in the constant component divided by the mean rate in the series, plotted as a function of varied-component reinforcers per hour on the main key. Data from the series with the lean constant component are given in the upper row, and those from the rich constant component are in the lower row. In the VI 150-s series, response rates were relatively low on the main key (see the Appendix), and changes in rate over conditions were small. For 2 subjects (D5 and D6), unsystematic variance in constant-component response rate was large relative to the average rate, although actual response rates did not fluctuate very much in 


\section{LEAN CONSTANT COMPONENT}
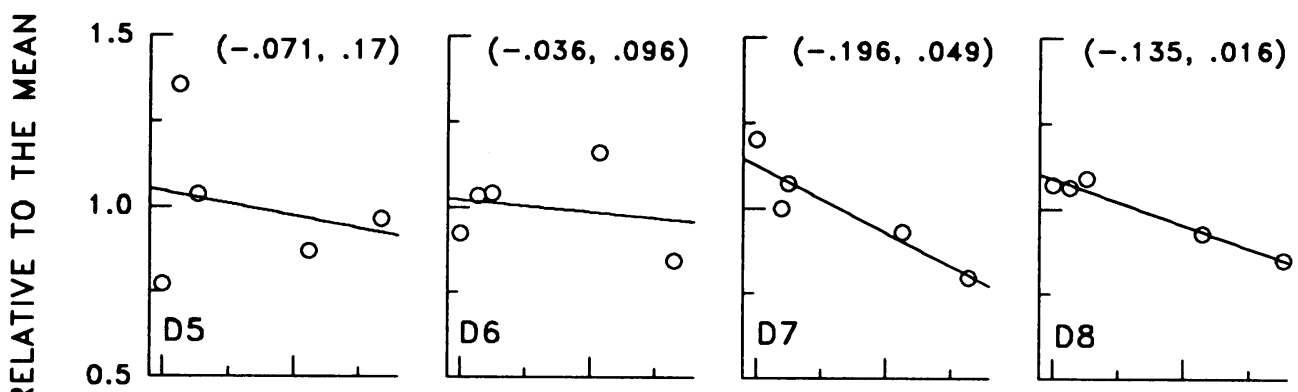

\section{RICH CONSTANT COMPONENT}
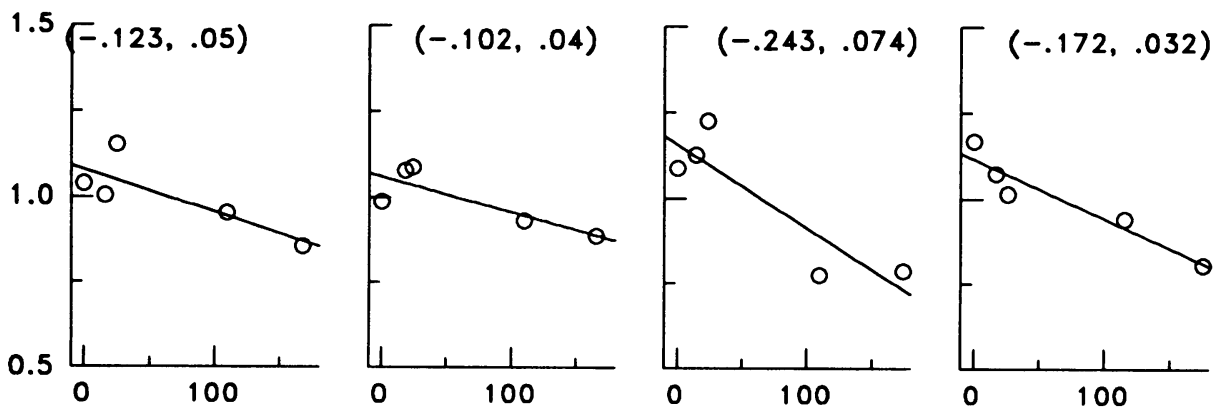

MAIN KEY REINFORCERS PER HOUR IN THE VARIED COMPONENT

Fig. 4. Relative response rates on the main key during the constant component, plotted as a function of reinforcers per hour on the same key in the varied component, for each bird. Response rates in each condition were divided by the mean rate within the series of conditions. Straight lines are least squares regression lines, fitted to describe contrast effects, and the slopes are given with their standard errors in parentheses. The upper row gives data from conditions with 60-s components and VI 150 s arranged on the main key in the constant component. The lower row gives data from 60-s components with VI 50 s reinforcement on the main key in the constant component (also shown in the center row of Figure 1).

absolute terms (Appendix). Systematic effects of changing reinforcement in the varied component (i.e., contrast) were negligible. For the 2 remaining subjects, clear contrast effects were observed and seemed to be adequately described by the fitted lines. In the series with VI $50 \mathrm{~s}$ on the main key in the constant component, contrast effects were present for all subjects. The slopes of the regression lines indicate stronger contrast with the rich baseline schedule for all subjects, in that negative slopes are always steeper in this series than in the lean baseline series, although the effect is rather small.

Figure 5 shows reinforcer reallocation in the series with rich and lean baseline schedules. Obtained rates of reinforcement on the extra key in the constant component for each condition were divided by the mean for the series, and are plotted as a function of main-key reinforcer rate in the varied component. Relative reinforcement rates in the varied component are also shown. Regression lines were fitted to rates from the constant component, as before, and again provide an adequate description of reallocation. Extra-key reinforcement rate clearly increased in the constant component as reinforcement rate in the varied component increased on the main key, and did so more in the series with the rich baseline schedule in the constant component. Slopes of descriptive regression lines were always positive and were always steeper in the series with the rich baseline schedule. Thus, the results obtained by manipulating the schedule on the main key in the constant component and those from manipulating component duration show similar changes in contrast and reinforcer reallocation. 
LEAN CONSTANT COMPONENT

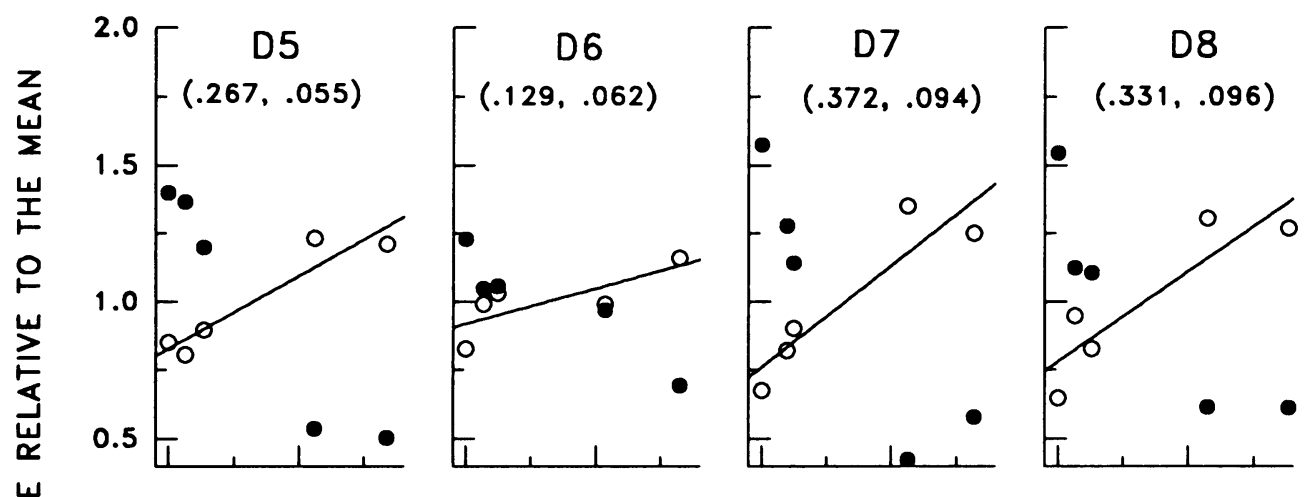

RICH CONSTANT COMPONENT
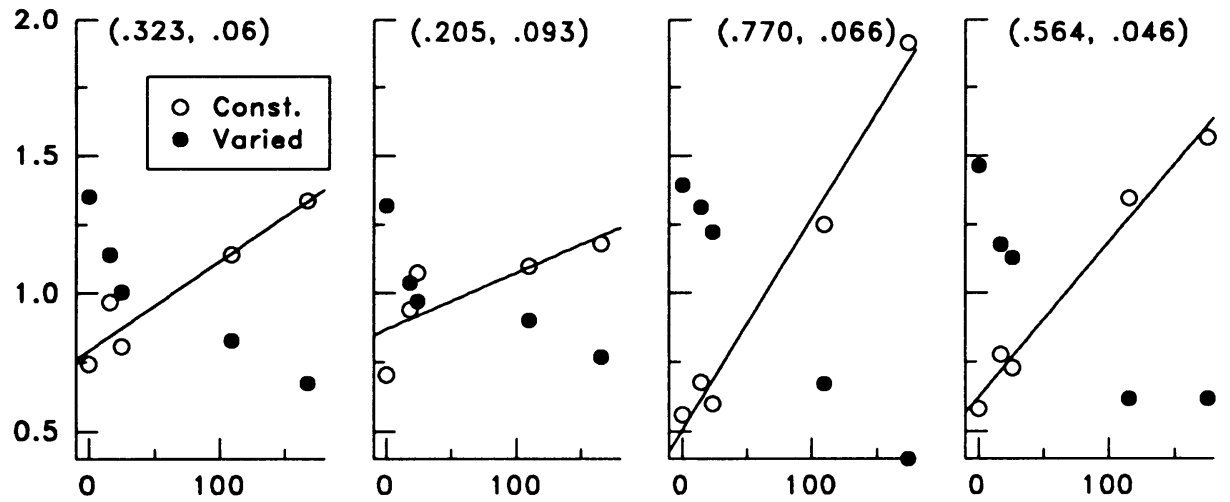

MAIN KEY REINFORCERS PER HOUR IN THE VARIED COMPONENT

Fig. 5. Relative reinforcement rates on the extra key in the constant component (unfilled circles) and the varied component (filled circles), plotted as a function of reinforcers per hour on the main key in the varied component. Reinforcer rates on the extra key in each condition were divided by the mean rate obtained within the series of conditions. Straight lines are regression lines fitted to describe reallocation, and the slopes and their standard errors are given in parentheses. The upper row gives data from conditions with 60-s components and VI $150 \mathrm{~s}$ arranged on the main key in the constant component. The lower row gives data from 60 -s components with VI 50 s reinforcement on the main key in the constant component (also shown in the center row of Figure 2).

\section{DISCUSSION}

The results of the present study were that contrast decreased when component duration increased and when the constant component was made lean, and that these changes in contrast were accompanied by corresponding reallocation of extra-key reinforcers between components. The decrease in contrast as component durations increased was strong and reasonably clear, although it was nonmonotonic in one case. Similar changes in contrast were reported in regular two-component multiple schedules by McSweeney (1982), who studied positive and negative contrast with pigeons pecking keys and component durations in the range of $5 \mathrm{~s}$ to $16 \mathrm{~min}$. There were clear decreases in contrast as components lengthened, especially up to component durations of $180 \mathrm{~s}$. However, the same result was not obtained when pigeons pressed levers rather than pecking keys in the multiple schedules, and the results obtained by varying the duration of only the constant or the varied components may be more complicated. McSweeney and Melville (1993) found increases followed by decreases in positive behavioral contrast when the duration of the varied component was increased from $5 \mathrm{~s}$ to 180 s. In somewhat different procedures, Williams 
(1979) found that contrast decreased as component durations were increased equally in four-component multiple schedules, and McSweeney and Melville (1988) found the same in a procedure in which several different varied-component values were presented within each session. The present results, with durations of both components varied, extend the finding to multiple schedules with an explicit source of alternative reinforcement.

The results obtained with different reinforcement rates in the constant component are consistent with some earlier work. McSweeney et al. (1986, Experiment 2) used constant-component schedule values in the range of VI 15 $\mathrm{s}$ to VI $240 \mathrm{~s}$ over four series of conditions. The schedule in the varied component was always reduced to one half of the value used in the constant component to produce positive contrast (in the present experiment, the same range of varied-component reinforcer rates was used in each series). The magnitude of contrast increased, in relative and absolute terms, with increases in the value of the constant component. However, other studies have reported the exact reverse: smaller contrast with rich constant components. A possible explanation of the differences among studies will be discussed below.

The extra-key data provide a clear replication of the reallocation of extraneous reinforcement in multiple schedules reported by McLean (1992). As reinforcement rate in the varied component was increased, the obtained rate of extra-key reinforcement increased in the constant component and decreased in the varied component. The changes in obtained rate in the varied component may be expected, because increases in main-key reinforcement produce concurrent interaction and thereby reduce the rate of extra-key responding and reinforcement in that component. The changes in the constant component are of greater interest. These could not arise from concurrent interaction, because main-key reinforcer rates did not change. Instead, reallocation (transfer of reinforcers from one component to the other) is assumed to affect extra-key reinforcer rate in this component. It is this link between components, produced by the fact that schedules of extraneous reinforcement operate continuously and thus allow reinforcers arranged in one component to be obtained in the other, that forms the basis of the reallocation hy- pothesis for behavioral contrast. In each series, using different component durations and different constant-component values, slopes of lines relating constant-component reinforcement on the extra key to varied-component reinforcement on the main key were always positive. Thus, even though the concurrently arranged contingencies on the main key were invariant in the constant component, the reinforcement context for responding on the main key varied over conditions within each series. As was the case in the McLean (1992) study, the changes in alternative reinforcement were consistent with the contrast observed on the main key, in that high rates of extra-key reinforcement are likely to promote low rates of main-key responding and vice versa. Accordingly, the extra-key reinforcer rates obtained here are consistent with the suggestion that reinforcer reallocation may cause, or at least contribute to, behavioral contrast.

Also consistent with the reinforcer reallocation hypothesis was the main result of the present study, that contrast and reallocation were correlated over manipulations of component duration and schedule values for the constant component-manipulations that produced changes in both contrast and reinforcer reallocation. The extra-key reinforcers cannot be assumed to represent extraneous reinforcement altogether, because these reinforcers represent only a portion of the total alternative reinforcement that was obtained. Nevertheless, the extra-key data are useful in that ordinally similar changes in naturally available extraneous reinforcement are likely to occur when reinforcement in the varied component is manipulated. Contrast was greatest in conditions in which reinforcer reallocation was strongest. This correlation was illustrated in Figure 3 for the component duration manipulation, and also held over changes in the value of the constant component.

An account of the effect of component duration on contrast, in terms of the reinforcer reallocation hypothesis, would be that changes in component duration influenced the extent to which alternative reinforcement was reallocated and thereby produced the changes in contrast. This account assumes that the fundamental effect of increasing component duration is to reduce reinforcer reallocation, and that the effect on contrast was a consequence of that effect. That is, it is assumed that the 
correlation observed here between reallocation and contrast reflects a causal relation. There are, however, at least two alternative interpretations that must be considered, specifically (a) the reverse proposition that contrast may be affected by component duration directly and that changes in reallocation were consequential to changes in contrast, or (b) that reallocation and contrast are independently affected by component duration. The first of these will be dismissed below. The second cannot be dismissed, but it should be noted that even if changing component duration does independently affect both contrast and reallocation, the effect on reallocation would surely feed back into contrast. That is, the changes in reallocation brought about by changing component duration must, according to the matching law, at least amplify any independent effect of component duration on contrast.

The first alternative noted above is that changes in extra-key reinforcement in the constant component might not represent reallocation, and instead might reflect the feedback function relating obtained rate of reinforcement on the extra key to extra-key responding. Suppose that component duration affects contrast directly, that reverse changes in extrakey responding are a part of the contrast effect, and that these changes are reduced as the components were lengthened. If so, then the changes in extra-key reinforcement might be explained in terms of changes in response rate on the extra key in the constant component. The effects of component duration on extra-key reinforcement would then follow from the changes in contrast with component duration. This interpretation is effectively the reverse of the process proposed in the reallocation hypothesis, and is implausible for several reasons. First, McLean (1992) used a control condition in which redistribution of extra-key reinforcers between components was prevented by canceling those not obtained by the end of components. This constraint had the effect of stabilizing the extra-key reinforcer rates obtained in the constant component, which it would not do if the obtained rate of these reinforcers was largely a function of extra-key responding in the constant component.

Second, in order for changes in extra-key responding during the constant component to produce the changes in extra-key reinforcement, the changes would need to be in the reverse direction from those observed on the main key. That is, there would need to be a change in the distribution of constant-component responses between the two keys. Moreover, this change in response distribution would need to be a function of changes in variedcomponent reinforcement. The possibility that contrast might indeed take this form has been explored by McLean (1983, 1988, 1991), by McLean and White (1983), and by White, Alsop, and McLean (1992). In these experiments the distribution of behavior between two concurrent response alternatives in a multipleschedule component, in which both reinforcement schedules were kept constant, was shown to be insensitive to variations in reinforcement in the other component (termed successive independence). Similar constancy of behavior allocation was reported by Marcattilio and Richards (1980). Successive independence cannot be assessed directly in the case of the present experiment because the extra-key reinforcers were allowed to vary in the constant component. But these failures to find evidence of successive dependence in experiments designed specifically to measure it suggest that this an implausible account of the reinforcer reallocation found here.

A third reason to doubt that contrast in the constant component may have produced reinforcer reallocation across components comes from consideration of the absolute rates of responding on the extra key in the constant component over conditions. In order to affect obtained rates of extra-key reinforcement, these changes would need to be very large, because of the flat feedback function relating obtained reinforcer rate to response rate when interval schedules are programmed. Indeed, in conditions in which concurrent VI VI schedules are constant, the changes in response allocation needed to produce sizable changes in obtained reinforcer ratios (e.g., in Pliskoff, 1971, using asymmetric changeover delays) are so large as to produce very strong overmatching of relative response rates to relative obtained reinforcer rates. Moreover, the extent of any changes in extra-key responding would need to decrease as component durations increased. Figure 6 (uppermost row) shows group-average response rates on the extra key in the constant and varied components, for each series of conditions, plotted as a function of main-key reinforcement in the varied component. In the 


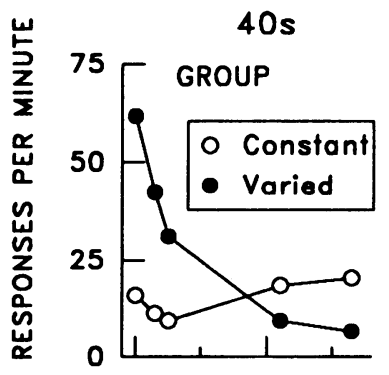

$60 \mathrm{~s}$

$160 \mathrm{~s}$

$60 s(V I 150)$
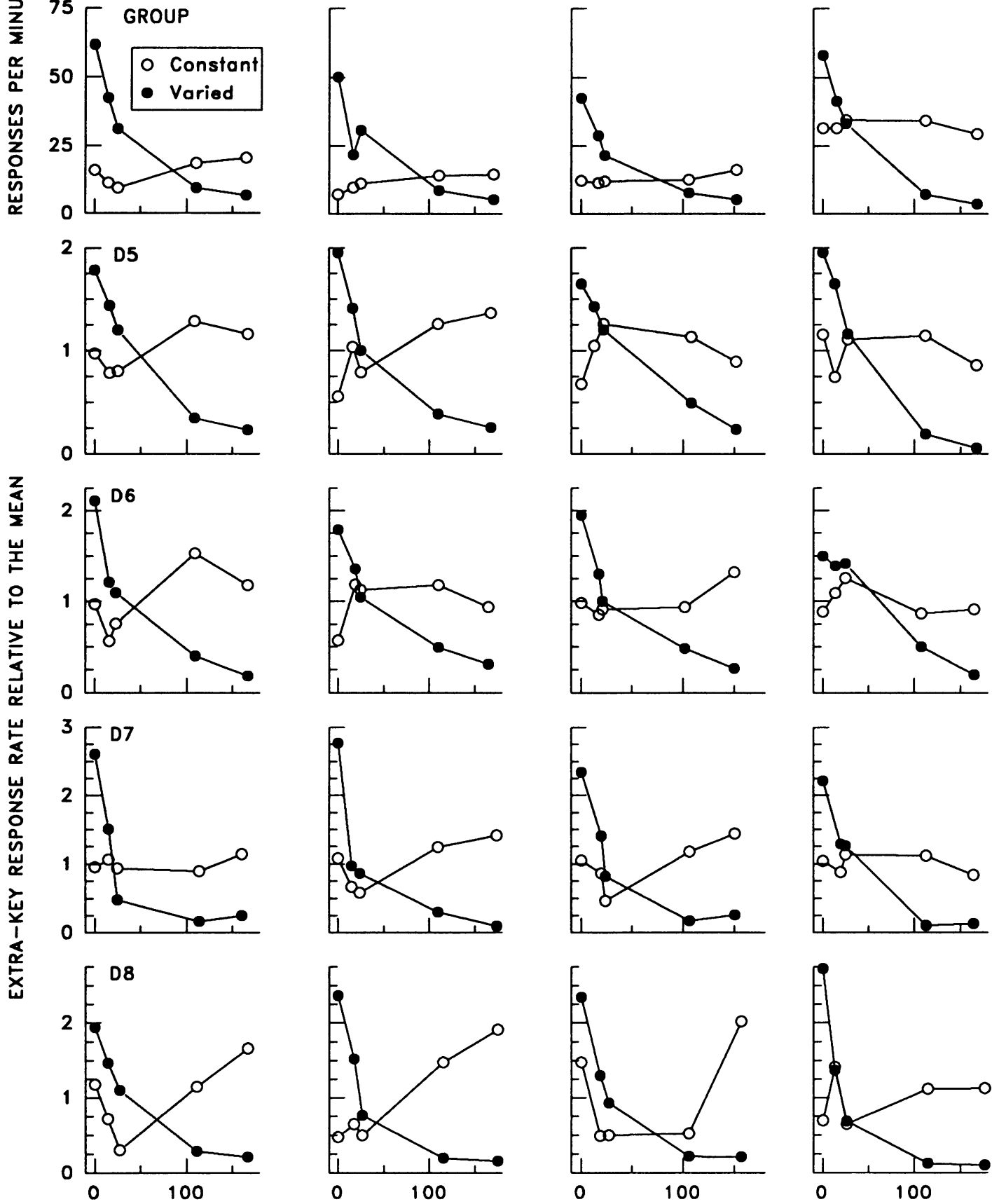

MAIN-KEY REINFORCERS PER HOUR IN VARIED COMPONENT

Fig. 6. Responding on the extra key in the constant (unfilled circles) and varied (filled circles) components. The upper row shows mean absolute rates for the group of 4 birds. Lower rows show relative rates from individual subjects; the absolute response rates for each key were divided by the mean rate in the series on that key. The first three columns show data from conditions with VI 50-s reinforcement on the main key in the constant component and 40-s, 60-s, and 160-s component durations, respectively. The fourth column shows data from conditions with VI 150-s reinforcement in the constant component and 60-s components. Data in the first column are from McLean (1992). 


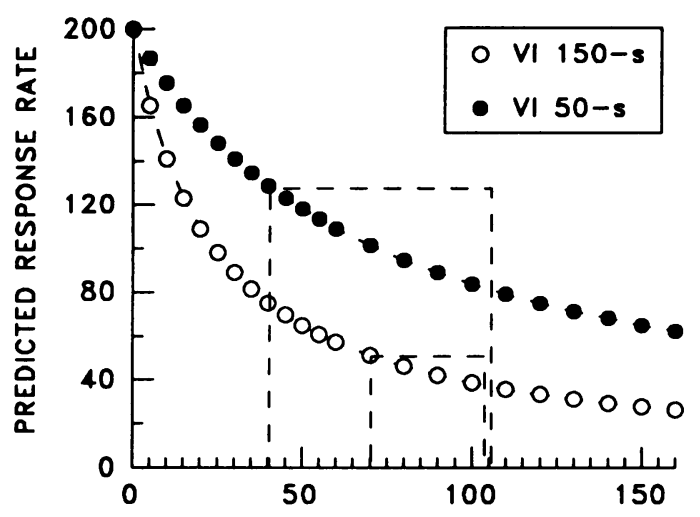

ALTERNATIVE REINFORCERS/HOUR

Fig. 7. Predicted response rate as a function of alternative reinforcement rate during constant components arranging reinforcers on VI 50-s (filled circles) or VI 150$s$ (unfilled circles) schedules. Rectangles show the effects of differences in reallocation of alternative reinforcement for VI 50-s and VI 150-s schedules in the constant component (see Discussion for details).

varied component, changes in extra-key response rate over conditions were large in all four series. However, in the constant component, systematic changes in response rate over conditions occurred only in the series with a 60-s component duration. Across series, changes in response rate in the constant component were not systematically related to component duration or constant-component value and were insufficient in themselves to produce changes in obtained extra-key reinforcement. The remaining panels in Figure 6 show ratios of response rate in a condition divided by mean response rate in a series of conditions, as was done in earlier figures. Data from individuals confirm the conclusions reached from the group data, in that responding in the constant component did not vary systematically as a function of reinforcement in the varied component, and was not systematically affected by increases in component duration.

Taken together, these considerations suggest very strongly that the changes in reinforcer reallocation over component durations and constant-component values did not result from changes in contrast, and that the results are better interpreted as indicating the reverse. With regard to the effect of manipulating the constant component's value, contrast was found to be greater when a relatively rich constantcomponent schedule was arranged on the main key, and similar arguments apply. That is, the best interpretation of the results seems to be that the changes in the value of the constant component affected reallocation and thereby affected the extent of contrast observed in the two series.

\section{Greater Contrast When the Constant Component Was Rich}

The larger contrast with the rich schedule in the constant component is rather surprising, notwithstanding the fact that McSweeney et al. (1986) reported a similar result in standard multiple schedules. This is because there are many studies that report the exact opposite when a within-session procedure is used. In this arrangement three components are used, two of which are constant and the third (often a variable-time schedule operating during a blackout between the two constant components) is varied. The two constant components differ in terms of reinforcer rate, and variation of the rate of food presentation during the blackout reliably produces greater contrast effects in the leaner of the two constant components (e.g., Harper \& McLean, 1992; Nevin, 1974; Nevin et al., 1983). However, the discrepancy in results between the two procedures might be less surprising when contrast is viewed in terms of the reinforcer reallocation hypothesis rather than direct interaction. Obtained rates of reinforcement from the extra key during the constant component were lower overall (see Appendix) and varied over a wider range (Appendix and Figure 5) in the series with the richer constant component. That is, when two-component multiple schedules were used, the pattern of reinforcer reallocation depended on the value of the schedule in the constant component. However, for the same to be true in the within-session procedure, subjects would need to reallocate extraneous reinforcers differently prior to the rich versus the lean constant components. Especially because the within-session procedure uses an irregular sequence of components in which the following component is unpredictable, this does not seem possible. Instead, reallocation seems likely to be similar for both constant components when the within-session procedure is used, whereas Figure 5 showed that it was stronger for the rich constant component when between-conditions procedures are used.

If it is true that patterns of reallocation dif- 
fer in the within-session and between-conditions procedures, as seems likely, the difference between them in terms of contrast may be predictable. Figure 7 shows what is predicted by the reinforcer reallocation and direct-interaction theories for cases in which similar or different patterns of reallocation occur to and from constant components of VI $50 \mathrm{~s}$ or VI $150 \mathrm{~s}$. According to both theories, contrast results from changes in alternative reinforcement (reinforcers in the varied component for direct interaction, and extraneous reinforcement in the constant component for reallocation theories). Accordingly, Figure 7 shows predicted response rates for the rich and lean constant components, plotted as a function of alternative reinforcement. Response rates were predicted from Herrnstein's (1970) hyperbola, $B_{c}=k R_{c} /$ $\left(R_{c}+R_{a}\right)$, where $B_{c}$ is response rate in the constant component and $R_{c}$ is reinforcer rate in the constant component. The term $R_{a}$ is alternative reinforcement and corresponds to extraneous reinforcement in the constant component in the case of the reinforcer reallocation hypothesis or to reinforcers in the varied component in the case of direct interaction models. Estimates were reached using $k=200$. It is clear from Figure 7 that direct interaction theories must predict greater contrast for the lean constant component, the reverse of the result reported here and in McSweeney et al. (1986), regardless of whether the within-session or between-conditions procedure is used. That is, if the abscissa is construed as varied-component reinforcement, Figure 7 shows proportionally greater reduction in response rate for the VI 150-s component. However, if the abscissa is construed as extraneous reinforcement, the extent of contrast depends on the extent of extraneous reinforcer reallocation, which is different depending on the constant component's value in the between-conditions procedure. Two ranges of extraneous reinforcement rate are marked in Figure 7 by rectangles. The overall higher, narrower range obtained for the series with the lean constant component predicts a small reduction in response rate for that series in relative terms. When the constant component is rich, the lower and wider range of extraneous reinforcement rates predicts a larger reduction in response rate. These ranges in extraneous reinforcement are hypothetical but are in ordinal agreement with the extra-key reinforcer rates ob- served here. If the ranges of extraneous reinforcement are determined using the average rates of extra-key reinforcement obtained in the present experiment, which are not assumed to represent the total extraneous reinforcement, the difference is more than sufficient to eliminate the advantage of the lean component, although it produces only an unconvincing reversal. Nevertheless, consideration of the extent of reinforcer reallocation produced with lean versus rich constant-component schedules readily predicts the effect observed here and in McSweeney et al. (1986).

The foregoing explanation is consistent with the results of all studies except that of Spealman and Gollub (1974). These authors used two-component multiple schedules, and found the same result as is found with the withinsession procedure (greater contrast with the lean constant component). However, Spealman and Gollub compared contrast in two groups of subjects trained either with a rich or a lean constant component, and their finding has not been replicated when a stronger, within-subjects design is used.

\section{Concurrent Reinforcement Interaction or Response Dependence?}

The existence of two competition theories of contrast raises the question of whether changes in response rate on the main key in the constant component (contrast) were produced by the changes in extraneous reinforcement in that component, as is claimed by the reinforcer reallocation view, or by changes in behavior other than pecking the main key (i.e., behavioral competition). There are two reasons for rejecting the behavioral competition hypothesis. The first is that changes in the distribution of behavior between pecking the main key and other behavior (pecking the extra key, or engaging in other unmeasured responses) would, if unrelated to changes in reinforcement in that component, be contrary to the conclusion of successive independence in multiple schedules (McLean, 1983, 1988, 1991; McLean \& White, 1983; White et al., 1992) and to Catania's (1963, Experiment 2) conclusion of response independence in concurrent schedules. In view of these generalizations about concurrent performances, it seems unlikely that contrast arises from behavioral competition. 
Table 2

Slopes of regression lines relating responses per minute on the extra key to responses per minute on the main key. Only data from the constant component were analyzed. The standard errors of the slopes are given in parentheses.

\begin{tabular}{ccccc}
\hline & \multicolumn{4}{c}{ Component duration } \\
\cline { 2 - 5 } Subject & $40 \mathrm{~s}$ & $60 \mathrm{~s}$ & $60 \mathrm{~s}($ VI 150) & \multicolumn{1}{c}{$160 \mathrm{~s}$} \\
\hline \hline D5 & $-0.348(0.11)$ & $-0.767(0.345)$ & $-0.074(0.65)$ & $0.809(0.323)$ \\
D6 & $0.002(0.202)$ & $-0.245(0.545)$ & $-0.426(0.859)$ & $-0.026(0.124)$ \\
D7 & $-0.023(0.018)$ & $0.024(0.062)$ & $0.109(0.408)$ & $-0.044(0.091)$ \\
D8 & $0.228(0.654)$ & $-0.069(0.197)$ & $-0.973(0.491)$ & $-0.061(1.1)$ \\
\hline
\end{tabular}

A second reason for rejecting the behavioral competition account concerns the changes in absolute response rate on the two keys during the constant component. Figure 1 showed that clear reductions in response rate occurred on the main key as reinforcement was increased in the varied component. If these reductions resulted from behavioral competition, then corresponding increases in response rate would be expected on the extra key. The Appendix and the upper panels of Figure 6 show that the contrast effects on the main key (Figure 1) often occurred in the absence of changes in response rate on the extra key, which is inconsistent with this explanation. Table 2 gives the slopes of regression lines relating responses per minute on the extra key to responses per minute on the main key in the constant component. To support the behavioral competition hypothesis, these regression lines need to be quite steep and negatively sloped. For example, if contrast was entirely accounted for by changes in extra-key responding, the slopes would equal -1 . Functions shallower than -1 would be expected from the behavioral competition hypothesis, in that extra-key response rates do not entirely account for other behavior, but clearly substantial negative slopes would be expected, because extra-key responding presumably constitutes a large proportion of other behavior in the constant component. The slopes in Table 2 do not support the behavioral competition hypothesis. Of 16 slopes, only 11 are negative, and 5 of these 11 are trivially small (i.e., within the range of -0.1 to 0 ). Slopes are not a function of component duration, and their standard errors are often large. Thus, for logical and empirical reasons the contrast observed on the main key seems to be better interpreted in terms of the changes in extra-key reinforcement (concurrent rein- forcement interaction) than in terms of behavioral competition (response dependence) within the constant component.

\section{Reinforcer Reallocation and the Matching Law}

The analysis of contrast given here is compatible with an extension of the matching law applied to behavior ratios during components of multiple schedules (McLean, 1991), and can therefore be developed quantitatively. Contrast is viewed in terms of changes in the distribution of behavior between two operant classes: those actions maintained by extraneous reinforcers versus those maintained by the food reinforcers arranged by the experimenter. Logically, the matching law then permits two possible interpretations of behavioral contrast in the constant component, summarized in the following equation (McLean, 1991):

$$
\begin{aligned}
\log \left(\frac{B_{p c}}{B_{o c}}\right)= & (a-n) \log \left(\frac{R_{p c}}{R_{o c}}\right)+n \log \left(\frac{R_{p v}}{R_{o v}}\right) \\
& +\log (b) .
\end{aligned}
$$

In Equation 1, $B$ represents behavior and $R$ represents reinforcers. The subscripts indicate whether the behavior is pecking the key for food reinforcement $(p)$ or "other" behavior maintained by extraneous reinforcement $(o)$, and whether the events occur in the constant component $(c)$ or the varied component $(v)$. $\log (b)$ is bias favoring one or the other of the two operant classes. The free parameter $a$ is sensitivity of the subject's distribution of behavior between operant classes in the constant component $\left(B_{p c} / B_{o c}\right)$ to the ratio of reinforcers that maintain the two classes, obtained in the same component $\left(R_{p c} / R_{o c}\right)$. Thus, $a$ is concurrent sensitivity to reinforcement (Baum, 1974). 
The parameter $n$ is sensitivity of behavior ratios in the constant component to the difference between reinforcer ratios in the constant and varied components. Thus, $n$ quantifies the effects on behavior in the constant component of changing reinforcer ratios in the other component (component interaction). For the changes in behavior ratios predicted by Equation 1 to have implications for behavioral contrast measured in terms of absolute response rate, it must be assumed that $B_{p c}+B_{o c}=B_{p v}$ $+B_{o v}=k$, and is more or less invariant with respect to changes in reinforcement. This interpretation of $k$ as the total of all behavior per unit of time is the same as that in Herrnstein's (1970) analysis.

The traditional interpretation of contrast is that behavior in the constant component is directly sensitive to changes in reinforcement in the varied component. This possible relation is captured in Equation 1 by the parameter $n$. If $n$ is negative, an inverse relation is predicted between the behavior ratio in the constant component $\left(B_{p c} / B_{o c}\right)$ and reinforcer ratio in the varied component $\left(R_{p v} / R_{o v}\right)$. Negative values for $n$ also affect the slope of a matching line relating behavior ratios in a component to ratios of reinforcers obtained in the same component (i.e., if $n$ is negative, then subtracting it from $a$ increases the predicted slope). An alternative view, also consistent with Equation 1 , is given by the reallocation hypothesis. According to this view $n$ may be zero, indicating no sensitivity of behavior in one component to reinforcers in the other component, but changes in the reinforcer ratio in the constant component are produced by transfer of extraneous reinforcers between components. That is, $R_{o c}$ and $R_{o v}$ vary in opposite directions, and reinforcer ratios in both components change. Contrast then results from changes in relative reinforcement during the constant component (i.e., $R_{p c} / R_{o c}$ ). The difference between the two views is that direct sensitivity to alternate-component reinforcement is assumed in the traditional view, whereas according to the reallocation hypothesis the observed interaction of components is mediated by changes in extraneous reinforcement in the constant component.

A good deal of research supports the interpretation in terms of reinforcer reallocation by showing that the value of $n$ is generally zero. The studies by McLean (1983, 1988, 1991) and White et al. (1992), described earlier, manipulated the distribution of reinforcers between the main key and an extra key in one "varied" component (i.e., $R_{p v} / R_{o v}$ ). By contrast with the present experiment, reinforcer ratios in the other component were held constant. These experiments investigated whether behavior ratios in the constant component $\left(B_{p c}\right)$ $B_{o c}$ ) were affected by reinforcement in the varied component, in a variety of conditions. In all cases, behavior ratios in the constant component did not change. This failure of reinforcer ratios in the varied component to influence behavior ratios in the constant component (successive independence) means that the term $n$ in Equation 1 is zero. If $n$ is zero, Equation 1 reduces to the regular matching relation:

$$
\log \left(\frac{B_{p c}}{B_{o c}}\right)=a \log \left(\frac{R_{p c}}{R_{o c}}\right)+\log (b) .
$$

Equation 2 permits contrast in the constant component only when $R_{o c}$ varies (i.e., when extraneous reinforcers are reallocated). Thus, the reallocation hypothesis is supported indirectly by the finding of successive independence, and is supported directly by the present findings with regard to reallocation of extrakey reinforcers.

Although the conclusion of successive independence holds in all of the conditions studied to date, there are circumstances in which direct sensitivity to alternate-component reinforcement has been found. Contrast effects found during the first quarter of components (local contrast) do not require mediation by reinforcer reallocation. McLean (1991) showed that for the first quarter of components, $n$ in Equation 1 was consistently negative, although when data from the whole component were considered, $n$ was zero. The finding of negative values for $n$ in the first quarter of components provides validation of Equation 1, whereas the finding of successive independence for responding averaged over the entire component indicates that direct interaction of components does not explain behavioral contrast overall. Combined, these findings suggest that only local contrast represents direct sensitivity of behavior in one component to reinforcement conditions in the other component, and that contrast overall is better explained in terms of reinforcer reallocation. 
Williams and Wixted's (1994) Criticism of Competition Theories of Contrast

Williams and Wixted (1994) recently presented a critique of the competition theories of contrast and concluded that the evidence supporting them was weak. Their conclusion was based on two considerations. The first was a fit of their (1986) model to McLean's (1992) data on reallocation and contrast, showing that there was an effect of manipulating reinforcement rate in the varied component that could not be ascribed to reallocation of extra-key reinforcers. The second was their interpretation of several data sets showing that contrast does not occur following manipulations that reduce responding in the varied component but leave reinforcer rate constant. From these, they argued that relative reinforcement in multipleschedule components, rather than competition mechanisms, yields a better explanation of contrast. They concluded that contrast is better understood in terms of the direct interaction model:

$$
\begin{array}{r}
B_{m c}=k R_{m c} /\left[\left(R_{m c}+a R_{e c}+b R_{m v}\right)\right. \\
\div(1+a+b)]+c .
\end{array}
$$

In Equation 3, response rate on the main key in the constant component $\left(B_{m c}\right)$ is predicted by reinforcers on the main key in both components $\left(R_{m c}\right.$ and $\left.R_{m v}\right)$ and by extra-key reinforcers in the constant component $\left(R_{e c}\right)$. The parameters $a$ and $b$ quantify the contributions to contrast made by reinforcers from the extra key in the constant component $\left(R_{e c}\right)$ and by those from the main key in the varied component $\left(R_{m v}\right)$, respectively. In fitting Equation 3 , Williams and Wixted found significant values of $a$ for 3 of the 4 birds, indicating a contribution to contrast from varied-component reinforcement that was not mediated by changes in extra-key reinforcement.

There are several logical problems with their analysis, however, and the reinforcer reallocation hypothesis is not seriously challenged by their arguments. First, it should be noted that the fits of Williams and Wixted's (1986) model to McLean's data, although impressive, were obtained with the addition to their model of a term $\left(R_{e c}\right)$ that takes account of reinforcement from the extra key. By including these reinforcers, and using obtained rates for $R_{e c}$ in their fits, Williams and Wixted incor- porate the reallocation process into their own model. Although reallocation is not a feature of their original model, this modification is essential because of the effect of varying concurrent reinforcement $\left(R_{e c}\right)$ on responding on the main key $\left(B_{m c}\right)$ (i.e., the concurrent "reinforcement interaction" effect documented by Catania, 1963, and Rachlin \& Baum, 1972, and also apparent in Figure 6, varied component).

Second, their conclusion that evidence for competition theories is weak does not follow from these fits of Equation 3. The parameter $a$ had greater value than $b$ in the fits for all birds, indicating that the greater part of the contrast observed in the constant component could be ascribed to changes in extra-key reinforcement; this is consistent with the reallocation hypothesis. What the fits show is that for 3 of the 4 subjects there is a small residual component of the observed contrast that was better predicted by the reinforcer rate in the varied component than by reallocated extrakey reinforcers. The authors nevertheless conclude that evidence for the competition theories in these data is weak.

Third, it is doubtful that obtained extra-key reinforcers are fully adequate as estimates for $R_{e}$ in the constant component, at least for the purposes of the quantitative analysis offered by Williams and Wixted (1994). Therefore, some residual component of contrast, not predicted by extra-key reinforcers, may be expected. The purpose of arranging reinforcement for pecking a second response key is to provide an indication as to what changes are likely to be occurring in extraneous reinforcement (of which $R_{e c}$ is a part) during the two components. However, obtained reinforcer rates from this second key cannot represent total extraneous reinforcement, as is implicitly assumed by Williams and Wixted, because there remains extraneous reinforcement for grooming, resting, and so forth, as proposed by Herrnstein (1970). The essence of the reallocation hypothesis for contrast is that these extraneous reinforcers are also reallocated between components and would therefore need to be taken into account in any quantitative analysis. Indeed, without assuming reallocation of naturally occurring extraneous reinforcers, this version of the competition hypothesis would be unable to explain the contrast effects that are routinely observed in regular 
multiple schedules in which there are no extrakey reinforcers to be reallocated. It would also be unable to explain the effects that, although reduced, were still observed for 3 of the 4 subjects in McLean's (1992) control condition. In this condition, reallocation of extra-key reinforcers (but not of extraneous reinforcers generally) was constrained by canceling those not obtained by the end of components.

The same misinterpretation explains why an effect of varied-component reinforcement sometimes emerged in Williams and Wixted's (1994) fits of Equation 3. Data from all conditions (including those with the constraint on reallocation of extra-key reinforcers) were used. Thus, any contrast in the control condition could only be accounted for in terms of the parameter $b$, because there is no term for naturally occurring extraneous reinforcers in Equation 3 and $R_{e c}$ was constrained. That is, nonzero estimates for $b$ would be inevitable if there was contrast in the control condition. Indeed, the 1 subject for whom no significant contribution of $R_{m v}$ was apparent in their reanalysis (Bird D6) was the one for whom the constraint eliminated contrast altogether instead of merely reducing it. Thus, Williams and Wixted's reanalysis shows little more than was apparent in the data from the conditions with a constraint on reallocation of extra-key reinforcers. All that is questioned by their analysis is the possibility that contrast is produced by reallocation of reinforcers from the extra key (rather than extraneous reinforcers in general). That possibility is not a feature of the reinforcer reallocation hypothesis, which considers naturally occurring extraneous reinforcers and extra-key reinforcers (if these are arranged).

Williams and Wixted's (1994) second main criticism of the competition theories was based on data from regular multiple schedules, in which no extra key is used. In these procedures, contrast does not occur when manipulations are used in the varied component that affect rate of responding while leaving reinforcer rate unchanged (such as scheduling response-independent reinforcers or signaling reinforcers in the varied component). According to the authors, this result undermines the competition hypothesis because behavior change in the varied component should be sufficient to produce contrast. However, according to the extraneous reinforcer reallocation version of this hypothesis, behavior change in the varied component might be necessary but is not sufficient. This is because a change in response rate in the varied component can produce contrast only if it results in reallocation of extraneous reinforcers. This is one important sense in which the present version of competition theory is different from Staddon's (1982) version.

What appears to have been assumed by Williams and Wixted (1994) is that, when response rate in the varied component is reduced by changing the schedule to response-independent reinforcement, or by signaling reinforcer availability, time previously taken by pecking the key is spent engaged in behavior that is maintained by extraneous reinforcement. If that was the case, then these manipulations would indeed produce reallocation of extraneous reinforcement and should produce contrast according to the reallocation hypothesis. However, it seems likely that the continued presentation of food reinforcers or the occasional presentation of the signal indicating availability of food reinforcement in these procedures will maintain some behavior other than obtaining extraneous reinforcers. That is, the topography of behavior maintained by food reinforcement may change without affecting the time occupied by the behavior. If so, then reallocation of extraneous reinforcers would not be expected in these procedures, and therefore the reallocation hypothesis does not predict that they will produce contrast in the constant component.

This issue admits direct empirical test, through observation of subjects during the varied component. The logic of Williams and Wixted's (1994) argument requires that behavior change resulting from signaling reinforcement in the varied component or from changing the schedule to a response-independent schedule is the same as that produced by extinction. Specifically, to meet the conditions necessary for contrast according to the reallocation hypothesis, all of these manipulations in the changed component must increase the behavior that is maintained by extraneous reinforcers, thereby depleting extraneous reinforcement and reducing the amount transferred to the constant component. On the other hand, if pecking is replaced by any new activity that is demonstrably maintained by food reinforcers (i.e., disappears when they are with- 
held), reallocation would not be expected and, therefore, contrast would not be predicted. The frequent occurrence of "superstitious" behavior under response-independent scheduling suggests that these procedures would not, after all, result in contrast according to the reallocation hypothesis.

\section{Conclusion}

Several difficulties for the reinforcer reallocation hypothesis remain; these have been outlined elsewhere (McLean, 1992; Williams, 1983) and have yet to be addressed experimentally. However, the present results generally support the conclusion that the variables known to affect contrast may indeed exert their influence by changing the extent to which extraneous reinforcers are reallocated between components. Changes in reallocation of explicitly programmed extraneous reinforcers were produced here by varying the rate at which components alternate and by varying the value of the schedule used in the constant component. These changes in rate of extraneous reinforcement in the constant component were consistent with the effects of component duration and constant-component value on the size of behavioral contrast observed in the constant component over several series of conditions. Logical and empirical considerations make it seem unlikely that changes in reallocation resulted from changes in contrast, and that the correlation between them is better interpreted as indicating that contrast either results from reallocation or is at least amplified by it. To that extent, the results are consistent with the reinforcer reallocation hypothesis for contrast.

\section{REFERENCES}

Baum, W. M. (1974). On two types of deviation from the matching law: Bias and undermatching. Journal of the Experimental Analysis of Behavior, 22, 231-242.

Catania, A. C. (1963). Concurrent performances: Reinforcement interaction and response independence. Journal of the Experimental Analysis of Behavior, 6, 253263.

Fleshler, M., \& Hoffman, H. S. (1962). A progression for generating variable-interval schedules. Journal of the Experimental Analysis of Behavior, 5, 529-530.

Harper, D. N., \& McLean, A. P. (1992). Resistance to change and the law of effect. Journal of the Experimental Analysis of Behavior, 57, 317-337.

Herrnstein, R. J. (1970). On the law of effect. Journal of the Experimental Analysis of Behavior, 13, 243-266.

Marcattilio, A. J. M., \& Richards, R. W. (1980). The maintenance of matching behavior when behavioral contrast occurs in multiple concurrent concurrent schedules of reinforcement. Animal Learning of Behavior, 8, 92-101.

McLean, A. P. (1983). Independence of successive human concurrent performances. Behaviour Analysis Letters, 3, 275-284.

McLean, A. P. (1988). Successive independence of multiple-schedule component performances. Journal of the Experimental Analysis of Behavior, 49, 117-141.

McLean, A. P. (1991). Local contrast in behavior allocation during multiple-schedule components. Journal of the Experimental Analysis of Behavior, 56, 81-96.

McLean, A. P. (1992). Contrast and reallocation of extraneous reinforcers between multiple-schedule components. Journal of the Experimental Analysis of Behavior, 58, 497-511.

McLean, A. P., \& White, K. G. (1983). Temporal constraint on choice: Sensitivity and bias in multiple schedules. Journal of the Experimental Analysis of Behavior, 39, 405-426.

McSweeney, F. K. (1982). Positive and negative contrast as a function of component duration for key pecking and treadle pressing. Journal of the Experimental Analysis of Behavior, 37, 281-293.

McSweeney, F. K., Dougan, J. D., Higa, J., \& Farmer, V. A. (1986). Behavioral contrast as a function of component duration and baseline rate of reinforcement. Animal Learning \& Behavior, 14, 173-183.

McSweeney, F. K., \& Melville, C. L. (1988). Positive contrast as a function of component duration using a within-session procedure. Behavioural Processes, 16, 21 41.

McSweeney, F. K., \& Melville, C. L. (1993). Behavioral contrast for key pecking as a function of component duration when only one component varies. Journal of the Experimental Analysis of Behavior, 60, 331-343.

McSweeney, F. K., \& Norman, W. D. (1979). Defining behavioral contrast for multiple schedules. Journal of the Experimental Analysis of Behavior, 32, 457-461.

Nevin, J. A. (1974). Response strength in multiple schedules. Journal of the Experimental Analysis of Behavior, 21, 389-408.

Nevin, J. A., Mandell, C. A., \& Atak, J. R. (1983). The analysis of behavioral momentum. Journal of the Experimental Analysis of Behavior, 39, 49-59.

Pliskoff, S. S. (1971). Effects of symmetrical and asymmetrical changeover delays on concurrent performances. Journal of the Experimental Analysis of Behavior, 16, 249-256.

Rachlin, H., \& Baum, W. M. (1972). Effects of alternative reinforcement: Does the source matter? Journal of the Experimental Analysis of Behavior, 18, 231-241.

Reynolds, G. S. (1963). Some limitations on behavioral contrast and induction during successive discrimination. Journal of the Experimental Analysis of Behavior, 6, 131-139.

Spealman, R. D., \& Gollub, L. R. (1974). Behavioral interactions in multiple variable-interval schedules. Journal of the Experimental Analysis of Behavior, 22, 471481.

Staddon, J. E. R. (1982). Behavioral competition, contrast and matching. In M. L. Commons, R. J. Herrnstein, \& H. Rachlin (Eds.), Quantitative analyses of behavior: Vol. 2. Matching and maximizing accounts (pp. 243-261). Cambridge, MA: Ballinger.

White, K. G., Alsop, B., \& McLean, A. P. (1992). Suc- 
cessive independence and behavioral contrast in a closed economy. Journal of the Experimental Analysis of Behavior, 58, 313-323.

Williams, B. A. (1979). Contrast, component duration, and the following schedule of reinforcement. Journal of Experimental Psychology: Animal Behavior Processes, 5, 379-396.

Williams, B. A. (1983). Another look at contrast in multiple schedules. Journal of the Experimental Analysis of Behavior, 39, 345-384.
Williams, B. A., \& Wixted, J. T. (1986). An equation for behavioral contrast. Journal of the Experimental Analysis of Behavior, 45, 47-62.

Williams, B. A., \& Wixted, J. T. (1994). Shortcomings of the behavioral competition theory of contrast: Reanalysis of McLean (1992). Journal of the Experimental Analysis of Behavior, 61, 107-112.

Received November 23, 1993 Final acceptance November 18, 1994

\section{APPENDIX}

Responses per minute and reinforcers per hour for each key in the constant and varied schedule components. Data are listed for each bird and for conditions in the order they were conducted (see Table 1). Shown are means of rates calculated for each of the last 10 sessions of training, excluding reinforcement time; the standard deviations of daily rates are in parentheses.

\begin{tabular}{|c|c|c|c|c|c|c|c|c|}
\hline & \multicolumn{4}{|c|}{ Responses per minute } & \multicolumn{4}{|c|}{ Reinforcers per hour } \\
\hline & \multicolumn{2}{|c|}{ Constant } & \multicolumn{2}{|c|}{ Varied } & \multicolumn{2}{|c|}{ Constant } & \multicolumn{2}{|c|}{ Varied } \\
\hline & Main & Extra & Main & Extra & Main & Extra & Main & Extra \\
\hline \multicolumn{9}{|c|}{ Series 1 (160-s components, VI $50 \mathrm{~s}$ in the constant component) } \\
\hline Bird D5 & $\begin{array}{l}46.4(3.7) \\
43.2(6.2) \\
52.6(5.7) \\
55.1(2.9) \\
54.9(3.2)\end{array}$ & $\begin{array}{l}16.1(1.8) \\
21.1(4.0) \\
24.8(3.2) \\
26.8(1.7) \\
29.7(2.3)\end{array}$ & $\begin{array}{c}3.3(2.4) \\
53.9(5.1) \\
29.4(11.3) \\
63.9(2.6) \\
38.2(3.7)\end{array}$ & $\begin{array}{r}48.6(5.3) \\
7.0(2.3) \\
42.1(7.7) \\
14.7(2.8) \\
35.4(3.7)\end{array}$ & $\begin{array}{l}69.2(4.1) \\
72.9(3.5) \\
68.2(7.9) \\
70.1(3.8) \\
70.6(5.2)\end{array}$ & $\begin{array}{c}81.1(7.8) \\
111.3(7.5) \\
90.2(7.0) \\
99.0(15.2) \\
89.7(10.5)\end{array}$ & $\begin{array}{r}0.0(0.0) \\
152.0(4.9) \\
12.6(5.2) \\
107.8(4.9) \\
21.9(6.8)\end{array}$ & $\begin{array}{l}93.1(9.3) \\
62.0(8.9) \\
81.7(9.6) \\
73.5(13.8) \\
82.3(7.9)\end{array}$ \\
\hline Bird D6 & $\begin{array}{l}64.4(4.0) \\
45.3(3.6) \\
68.0(2.0) \\
48.0(4.3) \\
50.5(6.8)\end{array}$ & $\begin{array}{l}11.9(1.5) \\
16.0(2.5) \\
10.4(1.4) \\
11.4(1.8) \\
11.1(1.9)\end{array}$ & $\begin{array}{r}6.5(2.0) \\
58.6(2.9) \\
24.0(4.1) \\
47.8(4.2) \\
24.3(4.0)\end{array}$ & $\begin{array}{r}38.5(2.6) \\
5.3(1.6) \\
25.7(1.9) \\
9.5(3.6) \\
19.7(3.1)\end{array}$ & $\begin{array}{l}71.1(4.8) \\
66.5(5.5) \\
69.8(4.4) \\
70.8(2.7) \\
68.9(6.1)\end{array}$ & $\begin{array}{r}74.5(12.1) \\
106.3(11.7) \\
76.4(15.3) \\
86.6(13.3) \\
80.2(10.0)\end{array}$ & $\begin{array}{r}0.0(0.0) \\
150.1(5.1) \\
17.1(7.1) \\
101.7(6.4) \\
20.8(6.6)\end{array}$ & $\begin{array}{l}96.4(13.6) \\
56.7(10.8) \\
88.6(12.9) \\
68.7(17.1) \\
83.7(9.4)\end{array}$ \\
\hline Bird D7 & $\begin{array}{c}90.2(5.9) \\
89.4(12.1) \\
116.8(7.4) \\
85.2(8.3) \\
111.4(11.8)\end{array}$ & $\begin{array}{l}6.8(2.1) \\
9.3(1.8) \\
5.6(2.2) \\
7.6(3.0) \\
3.0(1.0)\end{array}$ & $\begin{aligned} & 2.3(2.6) \\
& 127.5(5.2) \\
& 56.6(10.9) \\
& 115.4(7.3) \\
& 61.7(7.5)\end{aligned}$ & $\begin{array}{r}37.8(10.6) \\
4.1(1.0) \\
22.7(5.7) \\
2.8(0.7) \\
13.3(7.7)\end{array}$ & $\begin{array}{l}69.1(3.6) \\
71.2(4.6) \\
73.2(4.8) \\
71.1(3.3) \\
72.9(3.1)\end{array}$ & $\begin{array}{l}65.6(16.7) \\
88.0(7.3) \\
61.7(9.2) \\
84.3(14.3) \\
52.4(11.1)\end{array}$ & $\begin{array}{r}0.0(0.0) \\
150.5(4.3) \\
19.7(5.8) \\
106.2(5.8) \\
23.5(4.3)\end{array}$ & $\begin{array}{l}90.0(16.7) \\
56.3(8.1) \\
87.4(14.0) \\
54.9(18.0) \\
84.4(15.4)\end{array}$ \\
\hline Bird D8 & $\begin{array}{l}67.1(2.7) \\
63.1(4.7) \\
71.6(4.5) \\
63.3(6.1) \\
65.2(2.3)\end{array}$ & $\begin{array}{r}13.9(1.7) \\
19.1(4.5) \\
4.6(1.3) \\
4.9(2.0) \\
4.7(2.4)\end{array}$ & $\begin{array}{c}7.7(4.7) \\
95.0(7.3) \\
49.9(15.3) \\
75.4(10.3) \\
59.5(15.4)\end{array}$ & $\begin{array}{r}44.9(7.5) \\
4.0(1.5) \\
24.7(5.4) \\
4.2(2.2) \\
17.8(4.9)\end{array}$ & $\begin{array}{l}70.4(2.9) \\
71.5(3.7) \\
71.6(4.8) \\
73.4(2.0) \\
73.1(2.6)\end{array}$ & $\begin{array}{l}75.1(16.0) \\
96.9(10.6) \\
55.7(8.4) \\
70.8(9.9) \\
60.5(22.2)\end{array}$ & $\begin{array}{r}0.0(0.0) \\
156.9(6.0) \\
18.7(3.5) \\
105.9(7.9) \\
27.1(6.0)\end{array}$ & $\begin{array}{l}89.6(13.3) \\
58.4(11.2) \\
95.9(11.3) \\
64.7(8.8) \\
87.1(22.9)\end{array}$ \\
\hline \multicolumn{9}{|c|}{ Series 2 (60-s components, VI $50 \mathrm{~s}$ in the constant component) } \\
\hline Bird D5 & $\begin{array}{l}56.0(2.6) \\
46.1(3.3) \\
54.1(3.5) \\
51.3(5.3) \\
62.0(4.8)\end{array}$ & $\begin{array}{r}9.7(2.1) \\
23.6(3.2) \\
17.9(2.4) \\
21.7(2.4) \\
13.7(5.3)\end{array}$ & $\begin{array}{l}12.5(1.6) \\
61.4(3.7) \\
30.6(3.4) \\
59.2(5.2) \\
46.8(6.8)\end{array}$ & $\begin{array}{c}58.1(3.7) \\
7.6(2.4) \\
41.8(3.5) \\
11.5(2.4) \\
29.7(12.5)\end{array}$ & $\begin{array}{l}69.1(4.3) \\
67.8(5.5) \\
67.2(5.3) \\
68.3(5.5) \\
67.9(5.4)\end{array}$ & $\begin{array}{r}62.9(12.5) \\
113.3(17.5) \\
82.0(16.7) \\
96.7(13.7) \\
68.4(26.2)\end{array}$ & $\begin{array}{r}0.0(0.0) \\
167.7(3.0) \\
16.2(5.5) \\
109.3(5.5) \\
25.1(5.8)\end{array}$ & $\begin{array}{r}110.5(7.4) \\
55.3(14.8) \\
93.1(16.0) \\
67.7(14.6) \\
81.9(31.0)\end{array}$ \\
\hline Bird D6 & $\begin{array}{l}48.8(2.6 \\
43.93 .2) \\
53.3(3.0) \\
46.1(3.1) \\
53.8(2.7)\end{array}$ & $\begin{array}{r}9.4(1.4) \\
15.3(1.6) \\
19.4(2.5) \\
19.3(2.0) \\
18.5(1.2)\end{array}$ & $\begin{array}{r}2.3(1.0) \\
61.8(4.4) \\
28.9(2.8) \\
59.4(4.6) \\
31.5(4.9)\end{array}$ & $\begin{array}{r}48.0(3.7) \\
8.4(2.4) \\
36.3(3.4) \\
13.3(3.3) \\
28.0(3.4)\end{array}$ & $\begin{array}{l}68.5(4.1) \\
66.5(5.5) \\
64.3(5.1) \\
68.1(5.3) \\
64.9(6.4)\end{array}$ & $\begin{array}{l}56.5(7.1) \\
94.6(14.4) \\
75.4(13.4) \\
87.8(11.3) \\
86.0(14.8)\end{array}$ & $\begin{array}{r}0.0(0.0) \\
165.4(6.0) \\
18.1(5.4) \\
109.9(7.4) \\
24.2(4.1)\end{array}$ & $\begin{array}{r}117.5(13.1) \\
68.4(15.2) \\
92.2(11.7) \\
80.2(15.1) \\
86.5(16.8)\end{array}$ \\
\hline Bird D7 & $\begin{array}{r}111.9(2.4) \\
81.2(11.0) \\
115.8(11.6) \\
79.8(12.0) \\
126.0(17.9)\end{array}$ & $\begin{array}{l}6.9(2.5) \\
9.0(1.9) \\
4.2(1.7) \\
7.9(3.6) \\
3.7(3.1)\end{array}$ & $\begin{array}{r}5.3(3.7) \\
132.3(8.1) \\
22.8(6.3) \\
106.4(16.6) \\
31.3(12.4)\end{array}$ & $\begin{array}{c}53.4(8.2) \\
1.9(0.9) \\
18.7(4.8) \\
5.8(2.6) \\
16.7(10.1)\end{array}$ & $\begin{array}{l}65.9(3.5) \\
64.8(6.8) \\
63.7(6.8) \\
64.3(5.0) \\
64.6(6.0)\end{array}$ & $\begin{array}{r}35.4(11.9) \\
121.0(15.7) \\
42.8(12.4) \\
78.8(16.6) \\
37.7(21.1)\end{array}$ & $\begin{array}{r}0.0(0.0) \\
174.2(4.4) \\
14.4(5.6) \\
109.4(8.2) \\
23.4(6.5)\end{array}$ & $\begin{array}{r}126.5(12.5) \\
36.3(13.5) \\
119.2(11.4) \\
61.1(18.7) \\
111.0(13.5)\end{array}$ \\
\hline
\end{tabular}




\section{APPENDIX}

(Continued)

\begin{tabular}{|c|c|c|c|c|c|c|c|c|}
\hline & \multicolumn{4}{|c|}{ Responses per minute } & \multicolumn{4}{|c|}{ Reinforcers per hour } \\
\hline & \multicolumn{2}{|c|}{ Constant } & \multicolumn{2}{|c|}{ Varied } & \multicolumn{2}{|c|}{ Constant } & \multicolumn{2}{|c|}{ Varied } \\
\hline & Main & Extra & Main & Extra & Main & Extra & Main & Extra \\
\hline Bird D8 & $\begin{array}{l}83.8(5.0) \\
57.8(5.2) \\
76.9(4.6) \\
67.6(3.5) \\
72.7(4.3)\end{array}$ & $\begin{array}{r}2.5(0.8) \\
10.0(2.0) \\
3.4(2.2) \\
7.7(1.5) \\
2.6(1.0)\end{array}$ & $\begin{array}{l}6.1(2.0) \\
92.6(3.4) \\
51.2(14.2) \\
86.0(6.9) \\
55.6(6.5)\end{array}$ & $\begin{array}{r}40.8(3.9) \\
2.7(1.0) \\
26.2(7.3) \\
3.3(1.1) \\
13.1(3.8)\end{array}$ & $\begin{array}{l}66.5(5.6) \\
66.4(6.2) \\
69.9(5.7) \\
70.2(3.2) \\
68.1(3.8)\end{array}$ & $\begin{array}{l}33.4(6.6) \\
90.1(16.2) \\
44.7(13.9) \\
77.5(18.4) \\
42.0(12.4)\end{array}$ & $\begin{array}{r}0.0(0.0) \\
175.4(6.3) \\
16.9(6.6) \\
115.4(2.4) \\
26.0(3.9)\end{array}$ & $\begin{array}{c}134.5(9.1) \\
56.7(16.5) \\
108.1(7.5) \\
56.6(15.6) \\
103.9(14.8)\end{array}$ \\
\hline \multicolumn{9}{|c|}{ Series 3 (60-s components, VI $150 \mathrm{~s}$ in the constant component) } \\
\hline Bird D5 & $\begin{array}{l}24.5(4.9) \\
30.6(2.2) \\
43.1(3.1) \\
27.6(2.2) \\
32.9(3.6)\end{array}$ & $\begin{array}{l}49.1(3.7) \\
36.7(3.0) \\
31.7(2.2) \\
48.8(3.2) \\
47.2(9.0)\end{array}$ & $\begin{array}{r}1.4(0.9) \\
62.8(2.7) \\
24.8(5.0) \\
66.5(5.0) \\
42.4(8.2)\end{array}$ & $\begin{array}{c}67.3(3.9) \\
1.9(1.4) \\
56.9(5.9) \\
6.6(2.5) \\
39.9(12.3)\end{array}$ & $\begin{array}{l}22.6(6.4) \\
21.6(6.6) \\
24.8(6.6) \\
20.6(3.2) \\
22.9(4.7)\end{array}$ & $\begin{array}{r}89.6(13.7) \\
127.8(13.8) \\
85.1(10.8) \\
130.1(16.8) \\
94.7(20.4)\end{array}$ & $\begin{array}{r}0.0(0.0) \\
167.3(6.2) \\
13.0(5.1) \\
111.9(4.8) \\
27.4(7.0)\end{array}$ & $\begin{array}{l}95.5(16.3) \\
34.3(14.2) \\
93.2(13.4) \\
36.7(11.8) \\
81.8(20.8)\end{array}$ \\
\hline Bird D6 & $\begin{array}{l}27.2(4.0) \\
24.9(3.2) \\
30.4(3.5) \\
34.2(3.0) \\
30.7(4.6)\end{array}$ & $\begin{array}{l}29.0(4.5) \\
29.9(3.4) \\
35.8(4.0) \\
28.4(2.4) \\
41.2(3.3)\end{array}$ & $\begin{array}{r}1.3(0.5) \\
75.3(5.6) \\
19.1(4.0) \\
71.0(2.5) \\
34.5(3.9)\end{array}$ & $\begin{array}{r}50.4(6.0) \\
6.6(3.0) \\
46.7(6.6) \\
17.0(2.5) \\
47.5(5.3)\end{array}$ & $\begin{array}{l}20.2(5.9) \\
22.4(5.3) \\
19.7(5.8) \\
21.0(6.3) \\
20.0(6.5)\end{array}$ & $\begin{array}{r}74.7(10.6) \\
104.9(11.2) \\
89.4(11.1) \\
89.5(12.5) \\
93.1(16.5)\end{array}$ & $\begin{array}{r}0.0(0.0) \\
164.7(8.8) \\
13.6(6.2) \\
107.4(6.0) \\
24.5(4.1)\end{array}$ & $\begin{array}{r}102.6(14.2) \\
57.9(12.8) \\
87.6(13.2) \\
81.1(15.7) \\
88.4(13.7)\end{array}$ \\
\hline Bird D7 & $\begin{array}{l}49.3(6.7) \\
32.8(11.1) \\
41.0(6.2) \\
38.3(7.0) \\
44.0(10.2)\end{array}$ & $\begin{array}{l}33.2(4.3) \\
26.6(6.8) \\
28.0(7.0) \\
35.7(5.6) \\
36.2(9.5)\end{array}$ & $\begin{array}{r}2.6(0.4) \\
109.6(8.6) \\
42.2(7.7) \\
115.9(5.6) \\
56.7(13.7)\end{array}$ & $\begin{array}{c}55.7(9.2) \\
3.3(1.6) \\
32.4(9.5) \\
2.6(1.7) \\
31.6(10.9)\end{array}$ & $\begin{array}{l}17.5(6.0) \\
20.3(6.4) \\
21.5(5.4) \\
20.3(6.5) \\
17.0(4.7)\end{array}$ & $\begin{array}{r}64.2(10.2) \\
118.5(12.7) \\
77.7(11.2) \\
128.0(15.8) \\
85.7(22.6)\end{array}$ & $\begin{array}{c}0.0(0.0) \\
164.0(15.1) \\
19.7(3.9) \\
113.0(3.6) \\
24.7(6.0)\end{array}$ & $\begin{array}{c}112.5(7.8) \\
41.3(11.2) \\
91.3(10.2) \\
30.3(14.8) \\
81.6(20.3)\end{array}$ \\
\hline Bird D8 & $\begin{array}{l}55.0(8.6) \\
43.7(9.2) \\
54.6(6.5) \\
47.7(4.3) \\
56.0(5.3)\end{array}$ & $\begin{array}{l}15.1(6.2) \\
24.5(5.6) \\
30.7(7.5) \\
24.3(4.9) \\
14.1(3.9)\end{array}$ & $\begin{aligned} & 8.6(6.0) \\
& 99.5(3.9) \\
& 60.1(13.1) \\
& 101.6(3.3) \\
& 73.4(8.7)\end{aligned}$ & $\begin{array}{r}58.2(5.3) \\
2.2(0.8) \\
29.1(8.7) \\
2.7(1.5) \\
14.6(4.0)\end{array}$ & $\begin{array}{l}19.4(5.7) \\
21.4(6.0) \\
19.9(5.6) \\
23.7(3.2) \\
21.1(5.6)\end{array}$ & $\begin{array}{r}53.7(12.7) \\
105.1(15.6) \\
78.6(14.4) \\
108.0(11.3) \\
68.6(12.5)\end{array}$ & $\begin{array}{r}0.0(0.0) \\
176.6(7.4) \\
13.2(6.3) \\
114.6(4.3) \\
25.8(5.4)\end{array}$ & $\begin{array}{c}118.5(10.6) \\
47.0(11.9) \\
86.3(15.9) \\
47.3(13.0) \\
84.9(8.7)\end{array}$ \\
\hline
\end{tabular}

